\title{
Aerosol-cloud interaction inferred from MODIS satellite data and global aerosol models
}

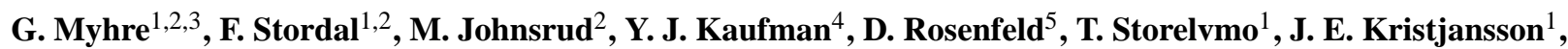 \\ T. K. Berntsen ${ }^{1,3}$, A. Myhre ${ }^{6}$, and I. S. A. Isaksen ${ }^{1}$ \\ ${ }^{1}$ Department of Geosciences, University of Oslo, Norway \\ ${ }^{2}$ Norwegian Institute for Air Research, 2027 Kjeller, Norway \\ ${ }^{3}$ Center for International Climate and Environmental Research - Oslo, 0318 Oslo, Norway \\ ${ }^{4}$ NASA Goddard Space Flight Center, Greenbelt Maryland 20771, USA \\ ${ }^{5}$ Institute of Earth Sciences, The Hebrew University of Jerusalem, Jerusalem 91904, Israel \\ ${ }^{6}$ Telemark University College, B $\emptyset$, Norway
}

Received: 16 June 2006 - Published in Atmos. Chem. Phys. Discuss.: 26 September 2006

Revised: 15 March 2007 - Accepted: 25 May 2007 - Published: 15 June 2007

\begin{abstract}
We have used the MODIS satellite data and two global aerosol models to investigate the relationships between aerosol optical depth (AOD) and cloud parameters that may be affected by the aerosol concentration. The relationships that are studied are mainly between AOD, on the one hand, and cloud cover, cloud liquid water path, and water vapour, on the other. Additionally, cloud droplet effective radius, cloud optical depth, cloud top pressure and aerosol Ångström exponent, have been analysed in a few cases. In the MODIS data we found, as in earlier studies, an enhancement in the cloud cover with increasing AOD. We find it likely that most of the strong increase in cloud cover with $\mathrm{AOD}$, at least for $\mathrm{AOD}<0.2$, is a result of aerosol-cloud interactions and a prolonged cloud lifetime. Large and mesoscale weather systems seem not to be a cause for the increase in cloud cover with AOD in this range. Sensitivity simulations show that when water uptake of the aerosols is not taken into account in the models the modelled cloud cover mostly decreases with AOD. Part of the relationship found in the MODIS data for AOD $>0.2$ can be explained by larger water uptake close to the clouds since relative humidity is higher in regions with higher cloud cover. The efficiency of the hygroscopic growth depends on aerosol type, the hygroscopic nature of the aerosol, the relative humidity, and to some extent the cloud screening. By analysing the Ångström exponent we find that the hygroscopic growth of the aerosol is not likely to be a main contributor to the cloud cover increase with AOD. Since the largest increase in cloud cover with
\end{abstract}

Correspondence to: G. Myhre

(gunnar.myhre@geo.uio.no)
AOD is for low AOD $(\sim 0.2)$ and thus also for low cloud cover, we argue that cloud contamination is not likely to play a large role. However, interpretation of the complex relationships between AOD and cloud parameters should be made with great care and further work is clearly needed.

\section{Introduction}

Aerosols are known to impact the formation and the life cycle of clouds. A wide range of measurements show that anthropogenic aerosol alter clouds and their optical properties (Ackerman et al., 2000; Andreae et al., 2004; Kaufman et al., 2005a; Kim et al., 2003; Koren et al., 2004, 2005; Penner et al., 2004; Ramanathan et al., 2001; Rosenfeld, 2000; Rosenfeld et al., 2002; Schwartz et al., 2002). It is important to understand and quantify the microphysical impact of both natural and anthropogenic aerosols on clouds, in order to understand and predict climate change (Anderson et al., 2003; Forest et al., 2002; Knutti et al., 2002). It is natural to seek information of aerosol-cloud interactions in observations, in particular how aerosols influence clouds and their microphysics. However, this is not straightforward, as aerosols and clouds are also related in ways other than through microphysics, most notably by both depending on large and mesoscale weather systems.

The identified aerosol indirect effects are several, complex and interlinked. An increase in the number of cloud condensation nuclei from anthropogenic aerosols yields an enhanced number of water cloud droplets with reduced sizes (Breon et al., 2002; Feingold et al., 2003; Kaufman and

Published by Copernicus Publications on behalf of the European Geosciences Union. 
Fraser, 1997; Twomey, 1977) for a similar liquid water path (LWP), resulting in increased cloud optical thickness and increased reflectivity of solar insolation. This cloud albedo effect is seen in various measurements of clouds but early experimental measurements 50 years ago also showed that the size of newly-formed cloud droplets was dependent on the aerosol concentration (Gunn and Phillips, 1957). The reduction in cloud droplet size can inhibit precipitation (Albrecht, 1989; Rosenfeld, 1999, 2000), the cloud lifetime increases and the clouds can evolve to an increased cloud top height (Andreae et al., 2004; Khain et al., 2005; Williams et al., 2002; Rosenfeld, 2006) with an increased LWP. Aerosols may thus lead to an increase in cloud optical thickness due to a combination of reduction in cloud droplet radius and increased water content. Lately, the semi-direct aerosol effect of the inhibition of cloud formation has attracted large attention (Ackerman et al., 2000; Cook and Highwood, 2004; Johnson et al., 2004; Kaufman et al., 2002; Koren et al., 2004; Menon et al., 2002; Ramanathan et al., 2001). Within the concept of the semi-direct aerosol effect we assume that absorbing aerosols cause the inhibition of cloud formation, evaporation of existing clouds, and blocking of surface heating inhibiting convection and cloud formation. It has potentially a strong impact on the radiative balance, but is also very sensitive to the vertical distribution of aerosols and clouds (Johnson et al., 2004; Penner et al., 2003). There have been some pioneering studies of ice clouds (see Lohmann and Feichter, 2005) showing potential for an anthropogenic influence on the number of ice nuclei. Estimates of the anthropogenic fraction of aerosols are available from models (http://nansen.ipsl.jussieu.fr/AEROCOM/), as well as from advanced aerosol retrievals over the ocean based on dedicated satellite instruments for aerosol studies (Kaufman et al., 2005b).

Observations show an increase in cloudiness at several locations in the early part of the last century and often a decrease in the last decades (Houghton, 2001; Karl and Steurer, 1990; Norris, 1999; Sun and Groisman, 2004; Tuomenvirta et al., 2000). A natural question is whether this is a coincidence or a result of aerosols prolonging the lifetime of clouds by suppression of precipitation, since there has been a strong increase in the anthropogenic aerosols up to late 1980s. Later there has been more geographical variation in trends in anthropogenic emissions of aerosols and precursors. Some studies show a strong increase in cloud fraction as a function of AOD based on satellite data (Kaufman et al., 2005a; Koren et al., 2005; Rosenfeld et al., 2006; Sekiguchi et al., 2003). Rosenfeld et al. (2006) found that by suppression of precipitation aerosols can convert the cloud structure from open to closed Benard cells and thus increase the cloud cover. Their analysis show that an increase in cloud cover due to aerosols is the largest for situations with relatively small amount of aerosols. Lohmann et al. (2006) found that the aerosol indirect effect in simulations with a global climate model (GCM) has the largest impact on the cloud water rather than the cloud fraction. This model study indicates that the cloud fraction increase is influenced more by meteorological factors than by the aerosol indirect effect, although it must be noted that LWP and cloud cover in GCMs are treated in a relatively simplified way.

Several possibilities exist for aerosols and clouds to be interlinked through processes other than physical aerosol-cloud interactions. One possibility is that meteorological situations with clouds nearby influence the AOD. Relative humidity increases the AOD due to more water uptake by the particles. Since relative humidity is usually higher in the vicinity of clouds than in completely clear sky regions, an increase in cloud fraction with AOD may be strongly influenced by this effect. Further, larger scale meteorological conditions may influence both AOD and cloud parameters and it is not intuitive to which extent and even in which direction this will impact the AOD - cloud relationships. Two examples illustrate this; 1) sea salt particles are generated under windy conditions, e.g. during frontal passages, when clouds are frequent, 2) over industrialized regions high pressure systems with weak winds will normally allow aerosol to build up, but in this case clear sky conditions are most usual. Finally, cloud contamination in the AOD retrieval may be a problem, causing an apparent increase in cloud fraction with AOD (Kaufman et al., 2005c; Zhang et al., 2005).

Kaufman et al. (2005a) and Koren et al. (2005) analyzed the regional effect of aerosol on clouds. They showed, using data from MODIS on Terra, that over the Atlantic Ocean, during June through August dust, smoke or pollution each enhances the cloud formation and the cloud top height. They found a total aerosol radiative effect of $-10 \mathrm{~W} \mathrm{~m}^{-2}$ for this region and season. Here we extend that study to investigate the relationship between aerosols and cloud cover and cloud properties for the whole globe and a 5-year period for MODIS data. In this work we establish relationships between AOD and cloud parameters from MODIS. In an attempt to isolate the impacts of common meteorological influence, such relationships have also been studied in two global aerosol models, which are completely independent and are driven by quite different meteorologies. In one of the models (Oslo CTM2) assimilated meteorological fields from ECMWF are used, whereas the other model is a GCM (CAM-Oslo), driving its own meteorology. Three parameters have been chosen to investigate the impacts of aerosols on clouds; namely cloud cover, water vapour, and liquid water path. All these parameters may be influenced by the "suppression of the precipitation effect/second aerosol effect", as well as the semi-direct effect.

Little attention has been given to how water vapour is affected by aerosol-cloud interaction. Suppression of precipitation and the prolonged lifetime of clouds may lead to more evaporation of clouds but also to higher cloud liquid water and thus a changed ambient water vapour. Higher rainfall under certain circumstances with high aerosol abundance has also been identified (Khain et al., 2005). This could 
lead to reduced water vapour. Also, the semi-direct effect with absorbing aerosols causing evaporation and inhibition of cloud formation may change the water vapour. The water vapour abundance is also important with respect to the speed of the hydrological cycle. An increase (or decrease) in the water vapour as a result of aerosol-cloud interaction will result in a slower (faster) hydrological cycle under conditions with no change in the surface evaporation. Human influence through irrigation is shown to directly impact the water vapour content. The impact is modest, $0.14 \%$, and the radiative forcing is $0.03 \mathrm{~W} \mathrm{~m}^{-2}$ (Boucher et al., 2004). This illustrates that even minor water vapour changes may give a radiative forcing that should be considered. Trenberth et al. (2005) show a $1.3 \%$ per decade increase in the water vapour column over the ocean during the period 1988 to 2003, which is likely to be mainly a result of feedback from increased temperature.

In the two models used here aerosol-cloud interactions (i.e. aerosol impact on cloud cover and cloud properties) have been turned off and coupling between aerosols and heating or cooling of the atmosphere is not incorporated. Thus, the output from the models is used in an attempt to identify relationships between AOD and the cloud parameters in the MODIS data, which could be related to meteorological conditions rather than physical aerosol-cloud interactions. We will specifically investigate how relative humidity and thus water uptake influences the results. Other cloud parameters that may be influenced by the cloud albedo effect, such as effective radius and cloud optical depth, have also been included in our analyses of satellite data, to some extent.

\section{Data and experimental design}

The purpose of this study is to investigate and possibly quantify relations between aerosols and clouds. Aerosols and clouds interact strongly in microphysical processes. This interaction depends on meteorological conditions. On the other hand, distributions and properties of aerosols and clouds are both influenced by other factors, most notably by large and mesoscale weather systems. Analyses of MODIS data on aerosols and clouds are a back bone in the present investigation. However, we also include results from models which do not include explicit microphysical interaction between aerosols and clouds, in an attempt to isolate such interaction. We use the Oslo CTM2 aerosol model, where aerosol transport (and in some cases aerosol production) is based on, and thus compatible with, assimilated meteorological fields from ECMWF. The aerosols in the Oslo CTM2 model have technically no microphysical impact on the clouds in the ECMWF product. However, the ECMWF clouds may still be influenced by aerosol cloud microphysics (e.g. from the suppression of precipitation effect or semi-direct effect) through the ECMWF assimilation. Even microphysical impact of aerosols on clouds could thus be inherent in the as- similated data. Therefore, we have also included in our study a model (an atmospheric climate model) without any aerosol influence on the clouds.

\subsection{MODIS}

Data from the MODIS instrument aboard the Terra satellite (launched December 1999) and Aqua (launched May 2002) for aerosols and cloud parameters are used. Collection 4 is used in this study. The aerosol retrieval is different over land (Kaufman et al., 1997) and ocean (Tanré et al., 1997) and with updated information on the retrievals and results from validations in Remer et al. (2005). The retrievals for the cloud parameters studied are described in Platnick et al. (2003). Data for 2001 (from the Terra satellite) is mostly used, unless otherwise stated. In some analyses data for 5 years from Terra and 2 years from Aqua are used. For water vapour the retrieval for the near-infrared region is adopted. We have used the daily level 3 product with a $1 \times 1$ degree spatial resolution.

\subsection{Oslo CTM2}

This is an off-line chemical-aerosol-transport model that is driven with meteorological data from ECMWF (Berglen et al., 2004). The meteorological input data have been generated by running the Integrated Forecast System (IFS) model at ECMWF in a series of forecasts starting from the analyzed fields every $24 \mathrm{~h}$. Each forecast is run for $36 \mathrm{~h}$, allowing $12 \mathrm{~h}$ spin-up followed by $24 \mathrm{~h}$ to be diagnosed and used in our investigation, with three hours resolution. The IFS model uses assimilated meteorological fields as input. The aerosol simulations are performed in a T42 resolution (2.8 degrees) with meteorological data for the year 2000. The modelled aerosols have no interaction with clouds. Clouds are not modelled in Oslo CTM2, but cloud data used in the investigation here are taken from the ECMWF model described above. Thus, in the analysis of aerosol-cloud relations we refer to this system as Oslo CTM2-ECMWF.

Oslo CTM2 includes the main aerosol components (sea salt, mineral dust, sulphate, organic carbon, and black carbon) (Myhre et al., 2007). Emissions for these species and their precursors are according to AEROCOM B (http://nansen.ipsl.jussieu.fr/AEROCOM/) (Dentener et al., 2006). Hygroscopic growth is included for three of these components (sea salt, sulphate, and organic carbon from fossil fuel). Since aerosol retrievals are only performed in clear sky pixels and the standard version of this model uses grid box relative humidity (the same for both clear and cloudy sky) with substantially coarser resolution, an investigation of the influence of relative humidity on the AOD-cloud relationship is not trivial and several model simulations have been necessary to gain insight into this problem. Table 1 outlines the four simulations with the Oslo CTM2 in which various degrees of hygroscopic growth have been taken into account 
Table 1. Description of simulations performed. The column for the treatment of relative humidity describes whether hygroscopic growth is taken into account and the upper bound in the hygroscopic growth when applied. The last column describes the cloud screening criteria in the model simulations.

\begin{tabular}{lll}
\hline Case & Treatment of relative humidity & Screening in cloud amount \\
\hline Oslo CTM2, standard & Grid box mean with upper threshold of 99.5\% & Upper threshold of 99.5\% \\
Oslo CTM2, rhclear & Clear sky relative humidity upper threshold of 99.5\% & Upper threshold of 99.5\% \\
Oslo CTM2, rhclear95 & Clear sky relative humidity upper threshold of 95\% & Upper threshold of 95\% \\
Oslo CTM2, dry & No hygroscopic growth taken into account & Upper threshold of 99.5\% \\
CAM-Oslo, standard & Grid box mean with upper threshold of 98\% & Upper threshold of 99.5\% \\
CAM-Oslo, rh95 & Grid box mean with upper threshold of 95\% & Upper threshold of 99.5\% \\
CAM-Oslo, 95 & Grid box mean with upper threshold of 95\% & Upper threshold of 95\% \\
CAM-Oslo, dry & No hygroscopic growth taken into account & Upper threshold of $99.5 \%$ \\
\hline
\end{tabular}

to investigate the relationships between AOD and various cloud parameters. Several cases are performed related to the hygroscopic growth of the aerosols, which is very dependent on the relative humidity. We have experimented with the upper threshold in relative humidity as a limit for hygroscopic growth. We have tested the impact of using clear sky relative humidity instead of the grid box mean (including the clear sky and cloudy sky) that is applied to hygroscopic growth. In addition, we have experimented with the cloud screening thresholds in the analysis (Table 1). This is a threshold for the cloud amount below which we include data in the analysis.

\subsection{CAM-Oslo}

CAM-Oslo is a modified version of the National Center for Atmospheric Research (NCAR) Community Atmosphere Model Version 2.0.1 (CAM 2.0.1) (http://www.ccsm.ucar. edu/models/atm-cam). For this study, the model was run with an Eulerian dynamical core, 26 vertical levels and a T42 horizontal resolution. We run the model with climatological Sea Surface Temperatures (SSTs). The model includes a lifecycle model for sulfate and carbonaceous aerosol species (Iversen and Seland, 2002), with AEROCOM B emissions corresponding to the present day. These are combined with dust and sea salt background aerosols in multiple lognormal aerosol modes (Kirkevåg and Iversen, 2002). Sea salt and mineral dust are prescribed in this version of the model. However, for the sea salt wind-speed dependence is included and the fine mode of sea salt and mineral dust is transported. In the model simulations used in this study aerosols have no interaction with the clouds.

Description of four cases for the CAM-Oslo is given in Table 1 . Due to the differences in the model designs the upper threshold for relative humidity is applied in slightly different ways between the 2 models. Otherwise, the cases described for Oslo CTM2 and CAM-Oslo in Table 1 are quite similar.

\section{Results}

\subsection{Aerosol optical depth}

Figure 1 shows the annual mean distribution of the AOD for MODIS, Oslo CTM2-ECMWF, and CAM-Oslo. The main areas of large AOD of natural and anthropogenic origin are similar. However, the magnitude of AOD differs. At high northern latitudes there are particularly large differences in AOD between MODIS and the two models. These results are likely to be a combination of AOD in the models, which is too low, due to low emissions in these areas, and long range transport of aerosols to these regions, which is too small. But the MODIS data can also, to some extent, have been influenced by problems with aerosol retrieval under snow conditions.

The regions defined in this study are shown in Fig. 2. The percentage distribution of AOD shown in Fig. 3 illustrates that there is reasonable agreement in many regions, given the uncertainty that exists in the global distributions of aerosols. The analysis is based on daily data. The largest differences are found over high-latitude land areas, as also seen in Fig. 1. The differences in some regions, in particular over land areas, are of such extent that some care must be taken in further investigation.

\subsection{Cloud fraction}

\subsubsection{Regional scale}

Kaufman et al. (2005a) analysed 4 regions in the Atlantic where the sources of the aerosols are relatively distinct; marine aerosol ( $30 \mathrm{~S}-20 \mathrm{~S})$, smoke $(20 \mathrm{~S}-5 \mathrm{~N})$, mineral dust $(5 \mathrm{~N}-25 \mathrm{~N})$, and pollution aerosols $(30 \mathrm{~N}-60 \mathrm{~N})$. Figure 4 shows our results for cloud cover as a function of AOD in the same areas for the MODIS data, and for the main cases described in Table 1 for Oslo-CTM2-ECMWF and Oslo CAM. In all the 4 regions MODIS has a strong increase in the cloud cover as AOD increases, consistent with the 
finding of Kaufman et al. (2005a). Note here the strong increase in cloud cover with AOD even in regions with aerosols which are relatively hydrophobic, such as biomass and dust aerosols. However, it cannot be ruled out that MODIS interprets dust as clouds, although this is less likely for AOD lower than 0.6, as considered here. In the regions dominated by biomass and dust aerosols the increase in cloud cover is rather constant for AOD up to 0.6, whereas for the regions dominated by marine and polluted aerosols there is a strong increase in cloud cover for AOD below $\sim 0.2$ and weaker increase for higher AODs. In Oslo CTM2-ECMWF there is a modest increase in the cloud cover as a function of AOD up to $\sim 0.2$ and variable for higher AOD. In all regions this increase is weaker than in the MODIS data except in the dust case. For higher AOD the increase in cloud cover with AOD levels off and eventually turns into a decrease, except in the pollution case, where the increase follows the MODIS data well. The difference between the standard and the dry case is largest in the marine and polluted regions, since these are the regions with the most hygroscopic aerosols. In the CAMOslo standard case the increase in cloud cover with AOD is really strong in the polluted region; this is the only region with a larger increase than in MODIS. In the other regions the results vary substantially with AOD. As for OsloCTM2-ECMWF the difference between the standard and the dry case is largest in the marine and polluted regions, but in addition, the two cases differ substantially in the Saharan region. In general, the difference between the standard case and dry case is larger in the CAM-Oslo model than in the Oslo CTM2-ECMWF.

Figure 5 shows the relationships between AOD and cloud fraction for various regions for the MODIS data, OsloCTM2-ECMWF, and Oslo CAM. MODIS shows an increase in the cloud cover with increasing AOD in all areas except for AOD above $\sim 0.2$ in the Indian Ocean, Asia Southwest, and Asia Southeast and above $\sim 0.4$ in South America and Northern Asia. The increase in cloud cover with AOD is particularly large for small AOD. In the MODIS data there are no large differences between land and ocean.

The cloud cover in the ECMWF data increases with AOD from the Oslo-CTM2 in the standard case in the same regions as the MODIS data with a few exceptions, most notably in the region of Africa. Even in the three regions with a most pronounced decrease in MODIS cloud fraction for high AOD, the agreement between MODIS and OsloCTM2-ECMWF is quite good. In these regions the cloud cover in the ECMWF data shifts from a weak increase to a weak or more substantial decrease with AOD in Oslo-CTM2, from the standard to the dry case. In general, the two cases, rhclear and rhclear95, are as expected between the standard and dry cases, with rhclear close to the standard case and the rhclear95 close to the dry case (not shown). This finding, in addition to sensitivity simulations not shown, indicates first, that the threshold for cloud screening in the analysis is not of great significance. Further, the largest importance of relative
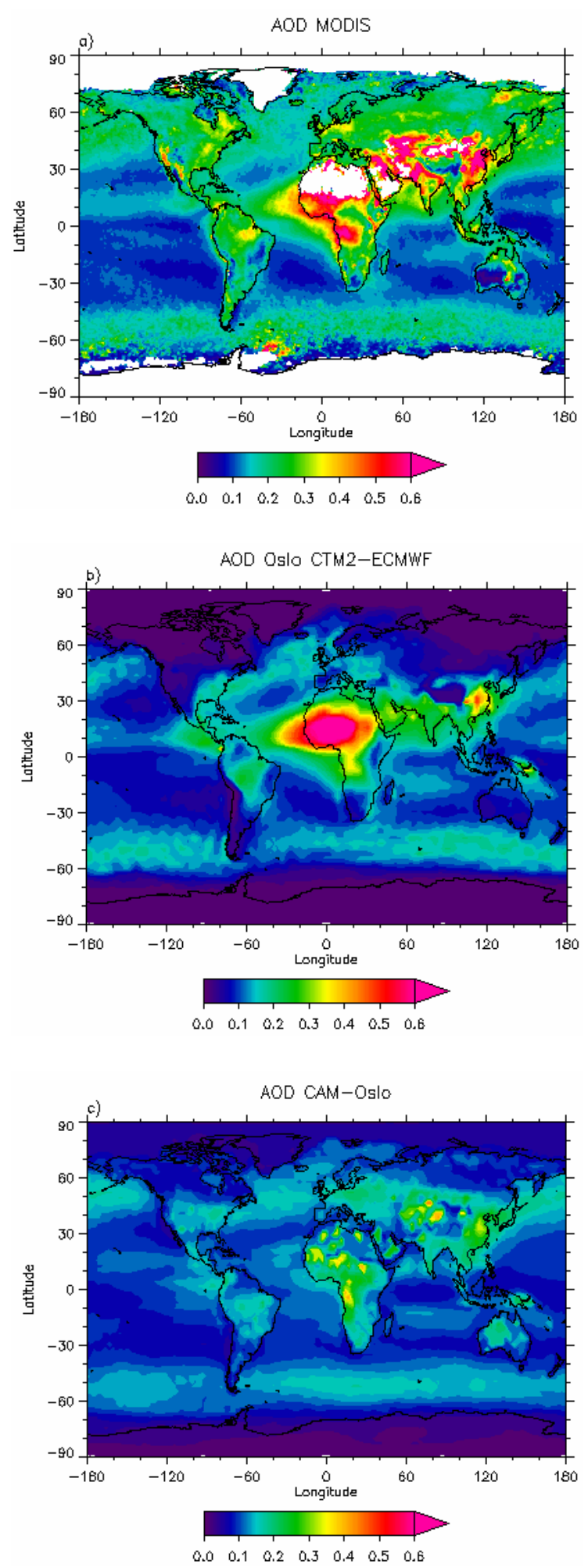

Fig. 1. Annual mean AOD at $550 \mathrm{~nm}$ from (a) MODIS, (b) Oslo CTM2-ECMWF, and (c) CAM-Oslo. MODIS data are from the standard Terra product (see text for references and details) for year 2001. 


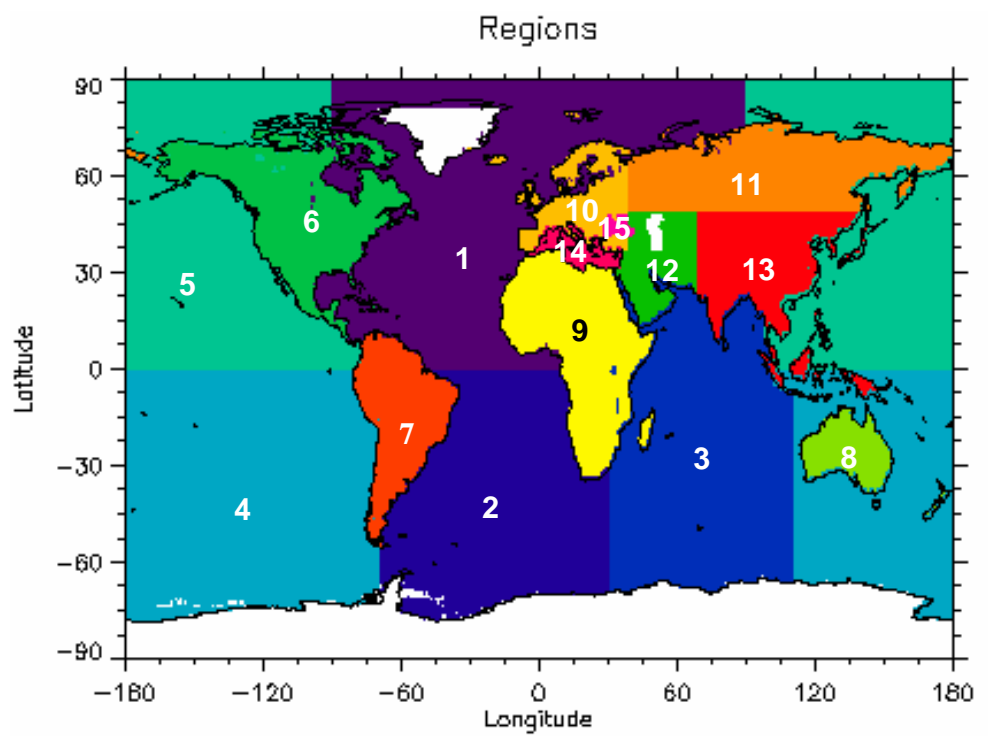

\begin{tabular}{|l|}
\hline 1: North Atlantic Ocean \\
2: South Atlantic Ocean \\
3: Indian Ocean \\
4: South Pacific Ocean \\
5: North Pacific Ocean \\
6: North America \\
7: South America \\
8: Australia \\
9: Africa \\
10: Europe \\
11: Asia North \\
12: Asia South West \\
13: Asia South East \\
14: Mediterranean Sea \\
15: Black Sea \\
\hline
\end{tabular}

Fig. 2. Geographical regions used in this study.

humidity is for values higher than 95\%. For small AOD the MODIS cloud fraction is smaller than in all four Oslo-CTM2 AOD cases for all regions, but the MODIS cloud cover has generally a stronger increase with AOD, at least for small AOD. If the MODIS results are a reflection of the meteorological conditions (e.g. dry clear conditions after precipitation), this would imply that the models have aerosol washout that is too weak.

For CAM-Oslo (standard case) the increase in the cloud cover with AOD is quite variable. In many regions there is a stronger increase in this relationship than the MODIS and the Oslo-CTM2-ECWMF data show but in some regions a weaker increase. For the two cases with an upper threshold of $95 \%$ relative humidity the results (not shown) are substantially different from the standard case, indicating that for CAM-Oslo the studied relationship is more strongly dependent on relative humidity than in Oslo CTM2-ECMWF. As for Oslo-CTM2-ECMWF the CAM-Oslo results are only weakly dependent on the threshold of the cloud screening. For the dry case in CAM-Oslo the change in cloud cover with AOD is quite different from the standard case and generally more similar to the two cases with an upper threshold of $95 \%$ relative humidity. In many regions there is a decrease in cloud cover with increasing AOD for the dry case in CAM-Oslo. Overall, the modelled dry cases have a slight tendency to show a decrease in cloud cover with increasing AOD; however, in the Indian Ocean, this seems to be most consistent between the models.

The seasonality in AOD is significant in some regions such as in the Indian Ocean. In this region the strong increase in cloud cover with AOD for low AODs in the MODIS data and the modelled decreased cloud cover with increasing AOD for the dry case are very similar for the four seasons.

\subsubsection{Global scale}

In Fig. 6a the relationship between cloud cover and AOD is shown on a global scale for 2001, on average, as well for individual data grouped together for more limited data aggregations (each point represents 500 individual data points). MODIS data for various years are shown in Fig. 6b. Figures $6 \mathrm{c}$ and $\mathrm{d}$ show the MODIS and models with all cases and the most important cases, respectively. For AOD below 0.2 MODIS shows a much stronger increase in cloud cover with AOD than the models do. This increase is consistent for the various years and the two satellite platforms for MODIS. For AOD above 0.2 the cloud fraction varies little with AOD in the MODIS data. The results diverge between the two models. In both models the cloud cover decreases with AOD in the dry cases, indicating that large-scale meteorological conditions globally favor high AOD under relatively clear sky conditions. The two models show a significant effect of the hygroscopic growth, but the difference in magnitude of the effect of water uptake in the two models is large. In this respect the difference is substantial both below and above relative humidity of $95 \%$.

\subsection{Liquid water path}

\subsubsection{Regional scale}

Figure 7 shows LWP as a function of AOD. For MODIS it illustrates a modest change. There is a tendency for a weak increase in LWP with AOD, which is stronger over land than ocean. There is even a slight decrease over a few oceanic regions. It is worth noticing that sub-pixel cloud contamination may influence these relationships. Another distinct pattern for the MODIS data is that inter-regional differences in 

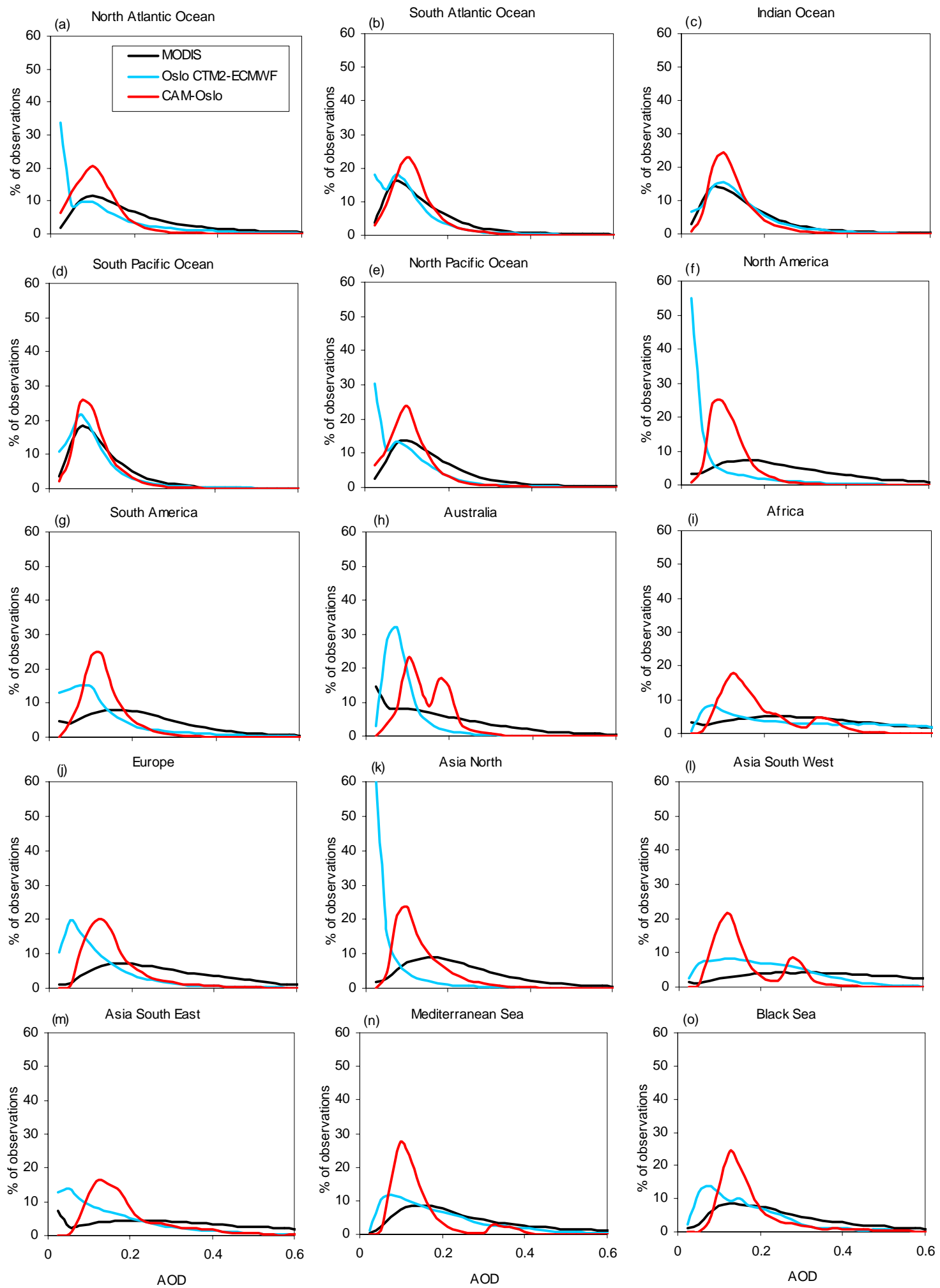

Fig. 3. AOD $(550 \mathrm{~nm})$ probability distribution (expressed as a percent frequency per $0.025 \mathrm{AOD}$ bin) for each of the three data sources shown in Fig. 1 sub-divided by regions in Fig. 2. 

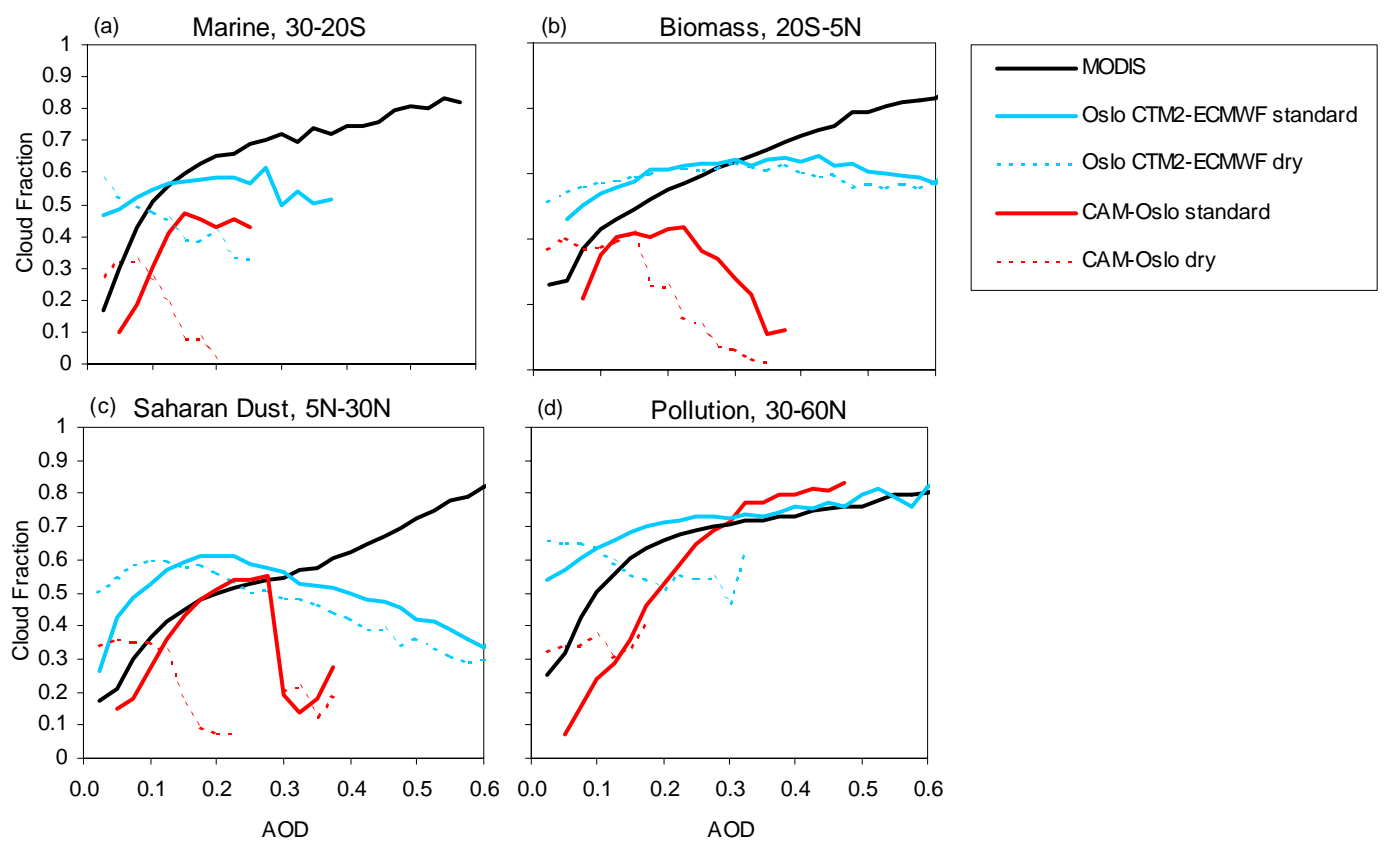

(d) Pollution, $30-60 \mathrm{~N}$

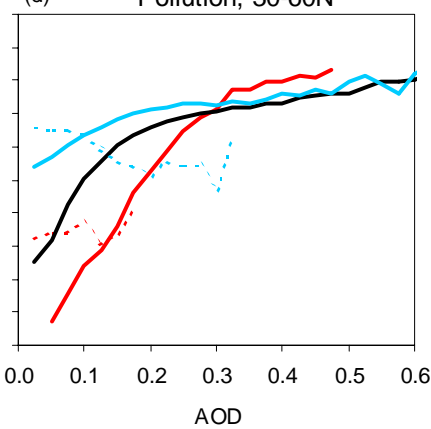

Fig. 4. Cloud fraction as a function of AOD $(550 \mathrm{~nm})$ for four Atlantic regions as defined in Kaufman et al. (2005a). MODIS data are from the standard Terra product (see text for references and details) for year 2001.

the relationship between LWP and AOD are quite small. For the Oslo-CTM2-ECMWF data inter-regional variations are larger, but in several of the regions these variations are quite similar to the MODIS data. For low AOD the Oslo CTM2ECMWF data show a significant increase in LWP with AOD in most of the regions. Further, in Oslo-CTM2-ECMWF hygroscopic growth plays only a minor role in the studied relationship. For CAM-Oslo the standard case shows in most of the regions a strong increase in LWP with AOD, with the dry case varying substantially between various regions. The hygroscopic effect has therefore a large impact on the results from the CAM-Oslo model, in particular for relative humidity above $95 \%$. The MODIS LWP has mainly a weaker increase with AOD than the models and hygroscopicity can only, to some extent, explain the differences. Especially at low AOD, where the two models are rather consistent, the increase is stronger than in the MODIS data.

\subsubsection{Global scale}

On a global scale there is a stronger increase in LWP for low AOD in the models than in MODIS. In CAM-Oslo this is in general mainly due to the hygroscopic effect (see Fig. 6e). The relationship found in the models for low AOD must arise from meteorological factors. Whether microphysical aerosol-cloud interaction is the cause for the results for LWP cannot be concluded neither from the MODIS data nor from the models used here, due to the large differences. Storelvmo et al. (2006) show that the spatial difference in LWP between CAM-Oslo and MODIS is significant.

\subsection{Water vapour}

\subsubsection{Regional scale}

We investigate here column water vapour changes in relation to aerosols and the importance of this is related to whether aerosols impact the speed of the hydrological cycle. The MODIS retrieval provides results for column water vapour in the clear sky and above clouds separately (Fig. 8). Except over the North Pacific Ocean the MODIS water vapour column increases mainly with AOD in all regions. The clear sky water vapour column shows a larger increase with AOD than the water vapour column above clouds. The changes in the relationships in water vapour column with AOD in the Oslo-CTM2-ECMWF simulations are relatively similar for the four AOD simulations (only two shown), even for the dry case in most regions. Also in CAM-Oslo the difference between the four cases (only two shown) is small, indicating that hygroscopic growth is not playing a major role for the model results of water vapour and their relationship with AOD. The Oslo-CTM2-ECMWF shows a larger increase and higher values in the water vapour with AOD than MODIS and CAM-Oslo do. Meteorological conditions most likely play a role in the relationship between AOD and water vapour since the models shows an increase in the water vapour with AOD, which is caused neither by aerosolcloud interactions nor by hygroscopic growth. One example of such a relation is that air masses from high latitudes are usually relatively dry and with lower aerosol abundance than air masses typically at mid-latitudes and in tropical regions. 

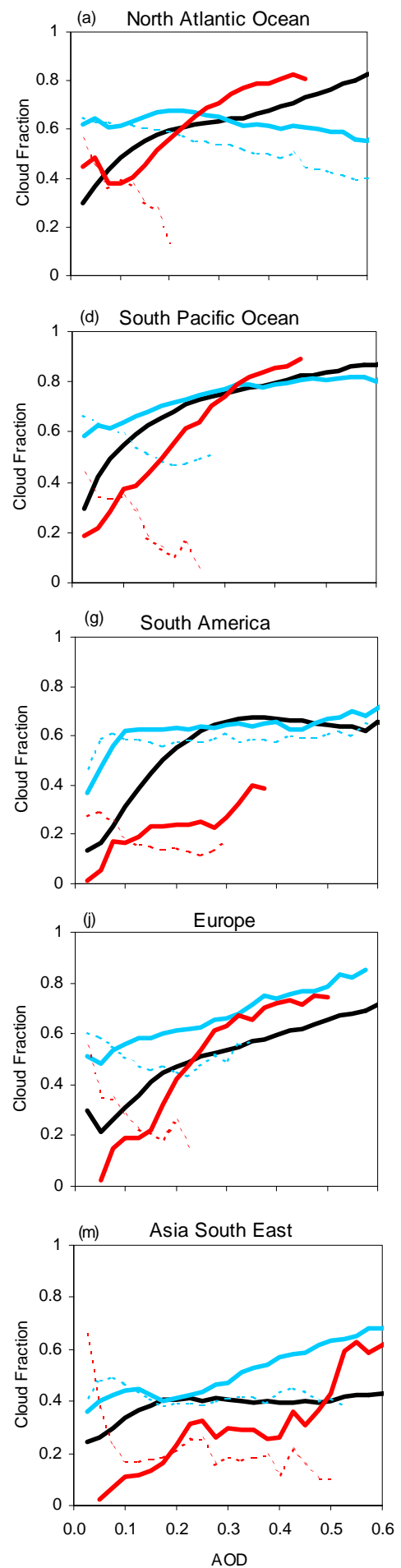

(b) South Atlantic Ocean

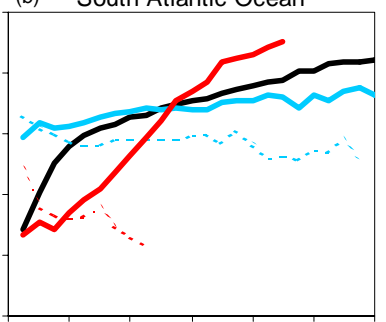

(e) North Pacific Ocean

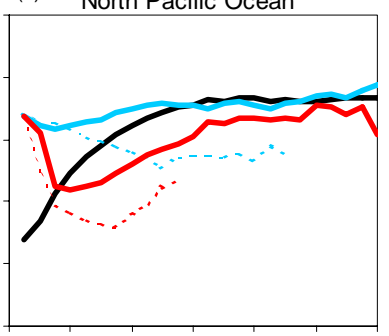

(h) Australia

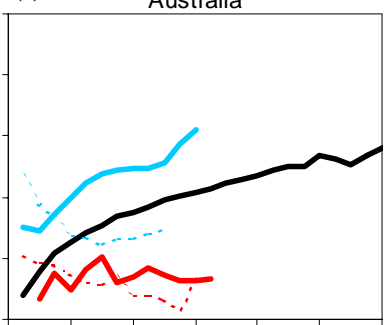

(k) Asia North
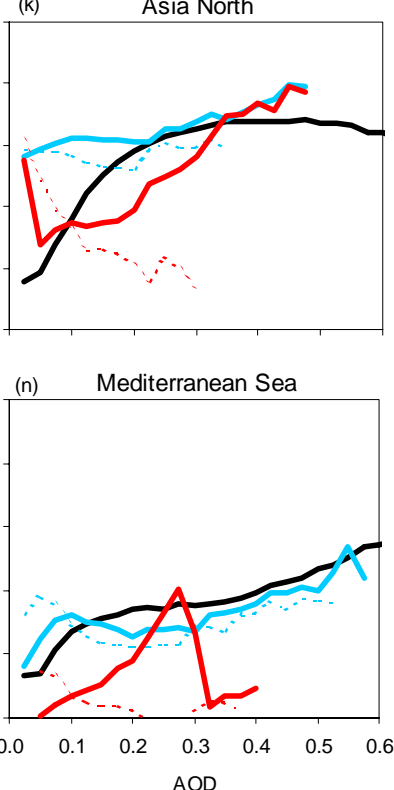

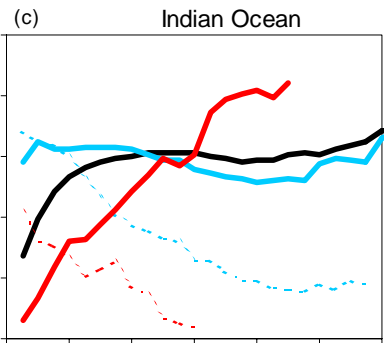

$\longrightarrow$ MODIS

Oslo CTM2-ECMWF standard

Oslo CTM2-ECMWF dry

CAM-Oslo standard

CAM-Oslo dry
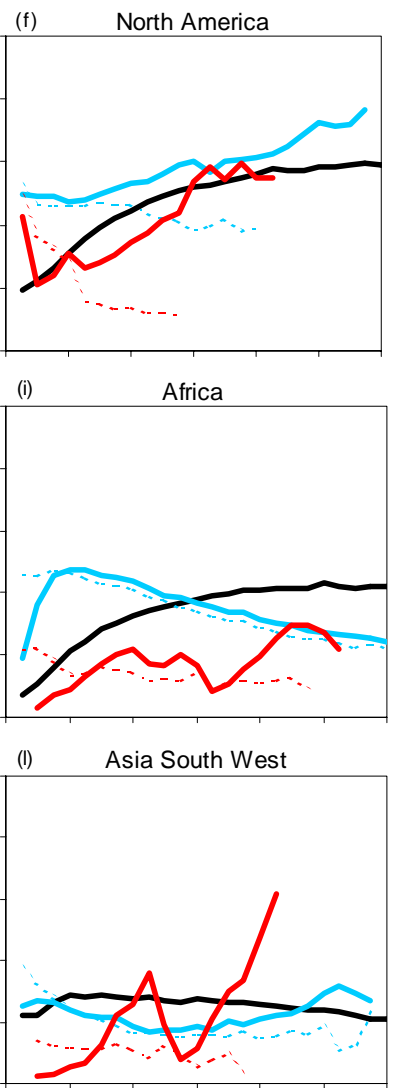

(0)

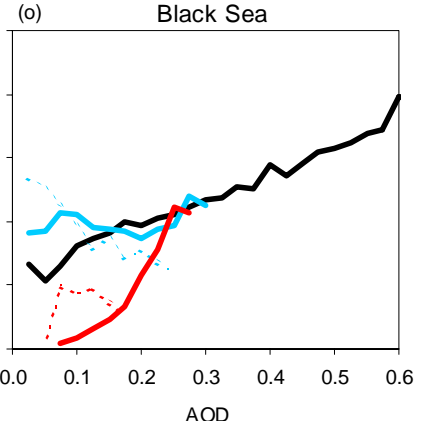

Fig. 5. Cloud fraction as a function of AOD $(550 \mathrm{~nm})$ for 15 regions. Ocean and land are separated in the regions. MODIS data are from the standard Terra product (see text for references and details) for year 2001. Regions defined in Fig. 2. 

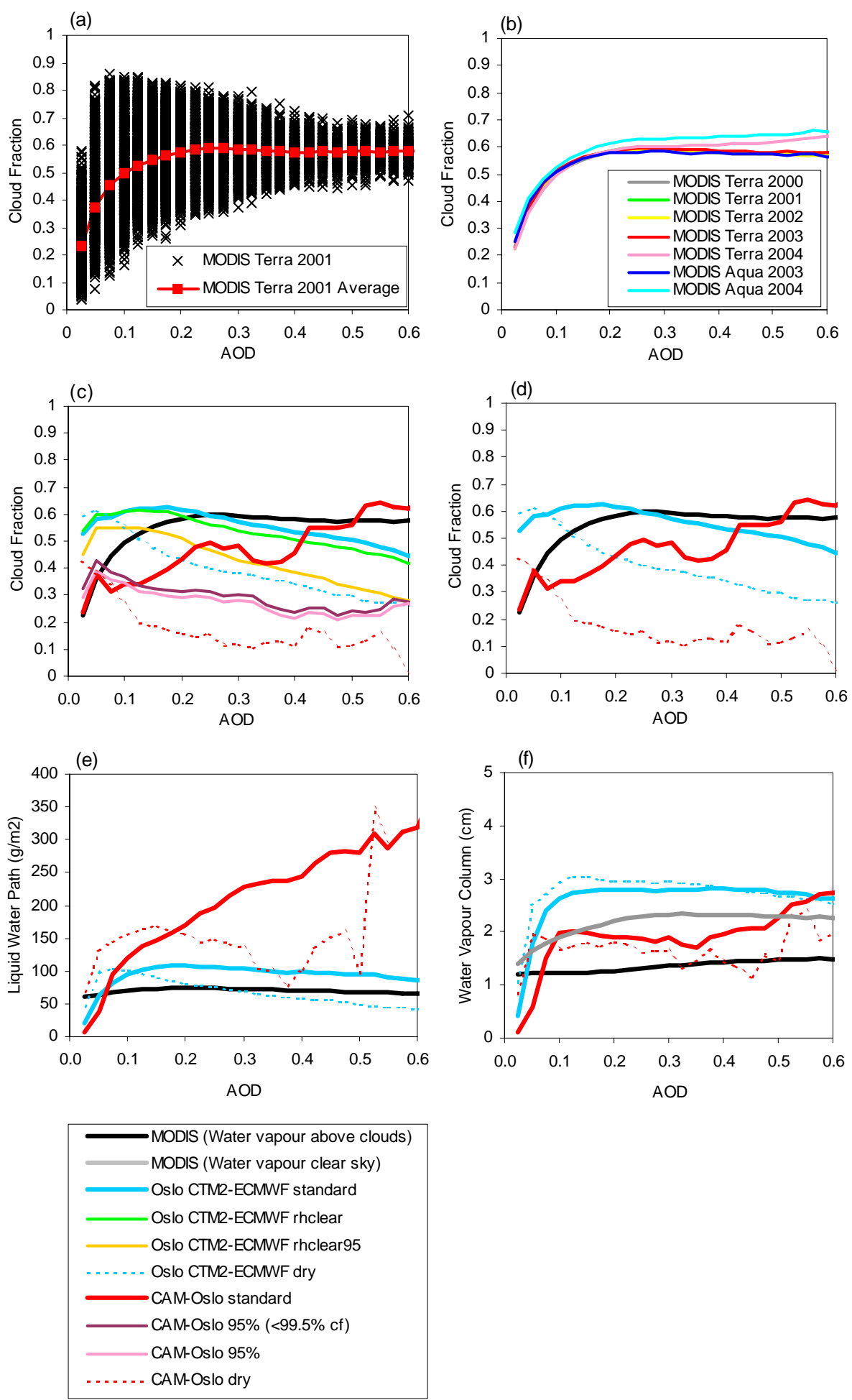

Fig. 6. Cloud properties as a function of AOD $(550 \mathrm{~nm})$. (a) cloud fraction for each $1 \times 1$ degree grid plotted with the global average for MODIS for year 2001; (b) average cloud fraction for each year by satellite platform; (c) cloud fraction for each of the cases described in the text; (d) same as (c) but for a subset of the cases; (e) average LWP (f); average water vapour column. MODIS data are from the standard Terra product (see text for references and details) for year 2001, except for panel (b) which includes data for several years for Terra and Aqua. 

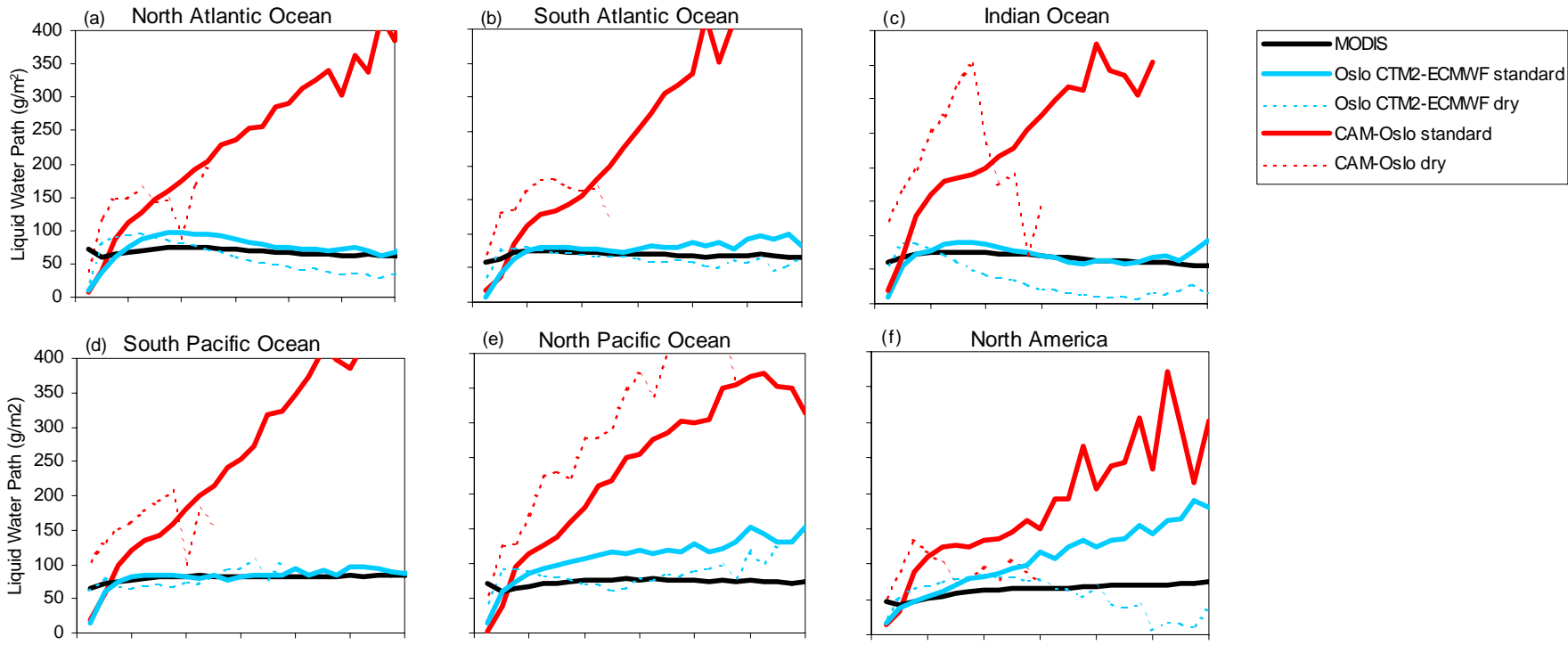

(e) North Pacific Ocean

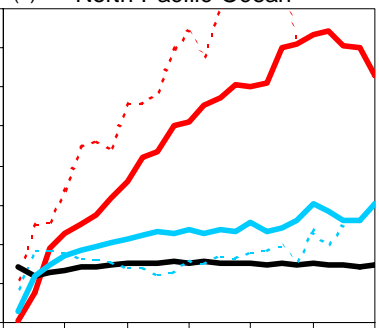

(f) North America

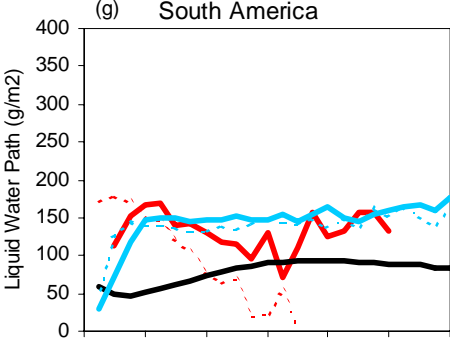

(h) Australia
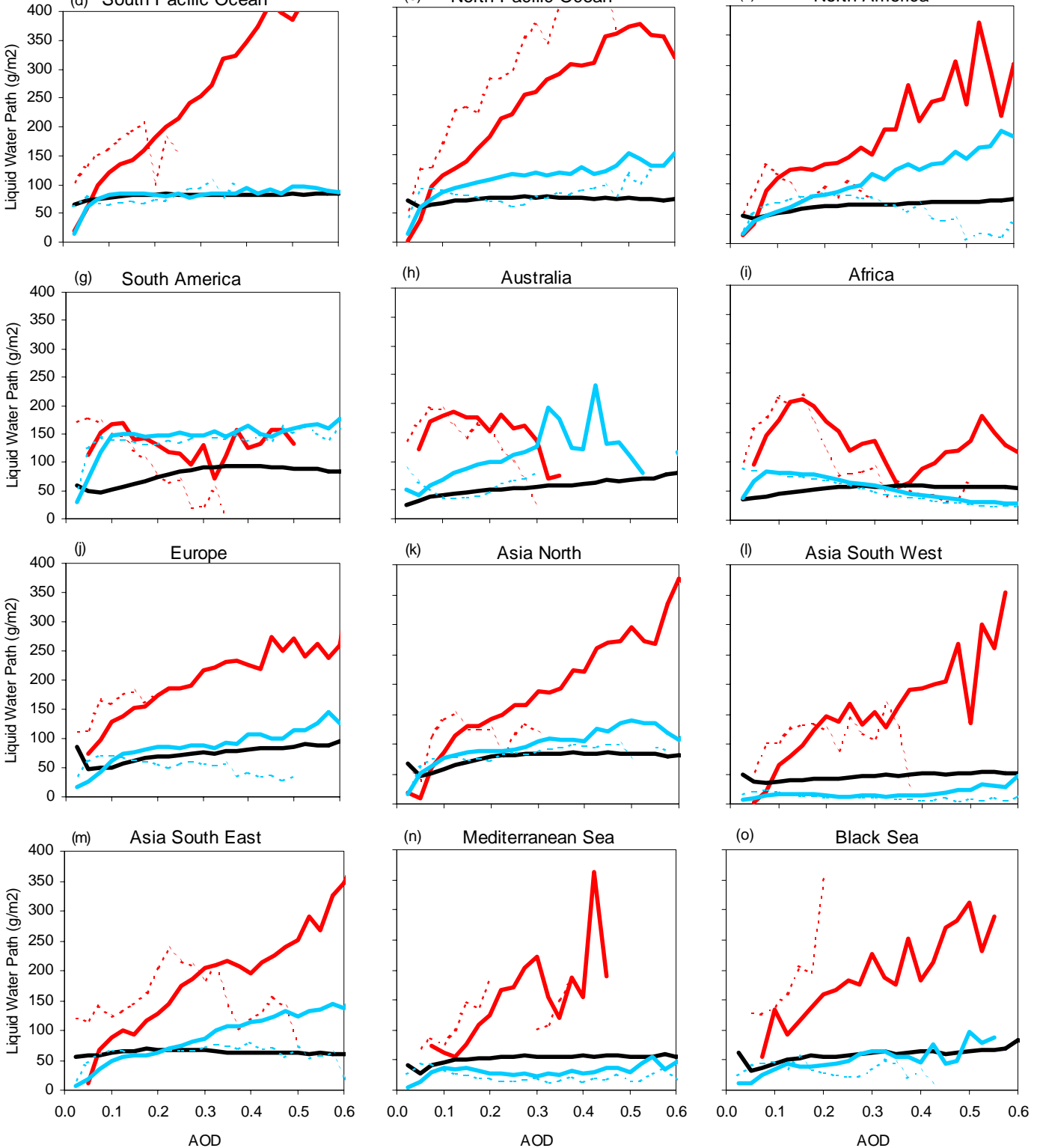

Fig. 7. LWP as a function of AOD $(550 \mathrm{~nm})$ for 15 regions. MODIS data are from the standard Terra product (see text for references and details) for year 2001. Regions defined in Fig. 2. 

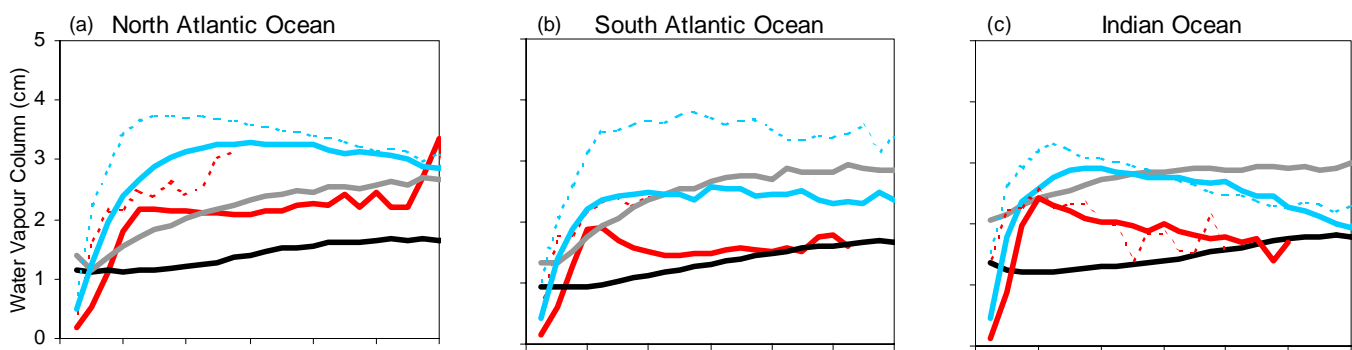

\begin{aligned} \hline MODIS above clouds \\ MODIS clear sky \\ Oslo CTM2-ECMMF standard \\ $\ldots \ldots$ Oslo CTM2-ECMMF dry \\ CAM-Oslo standard \\ $\ldots \ldots$. . CAM-Oslo dry \end{aligned}
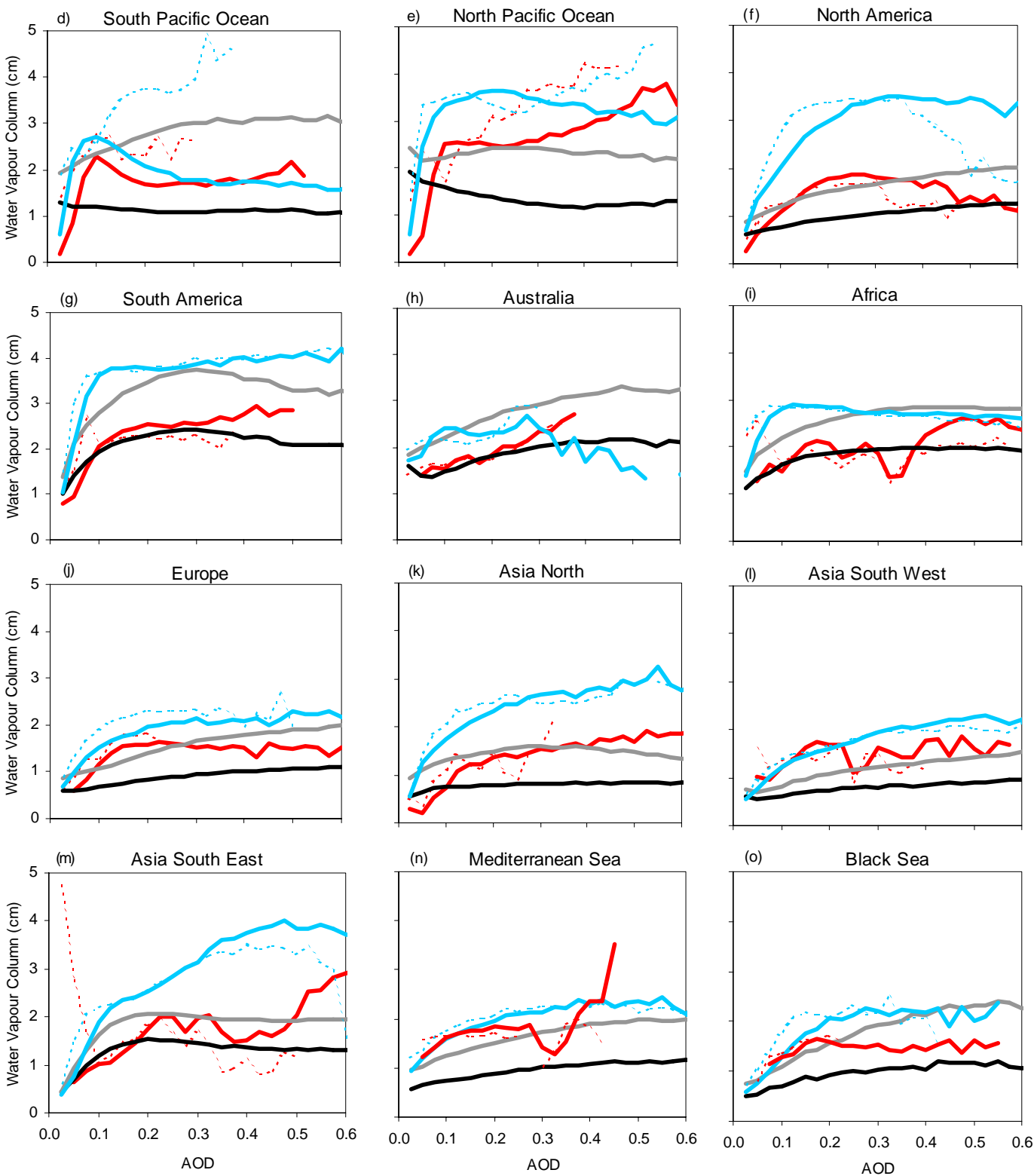

Fig. 8. As in Figs. 7a-o, but for water vapour column. 

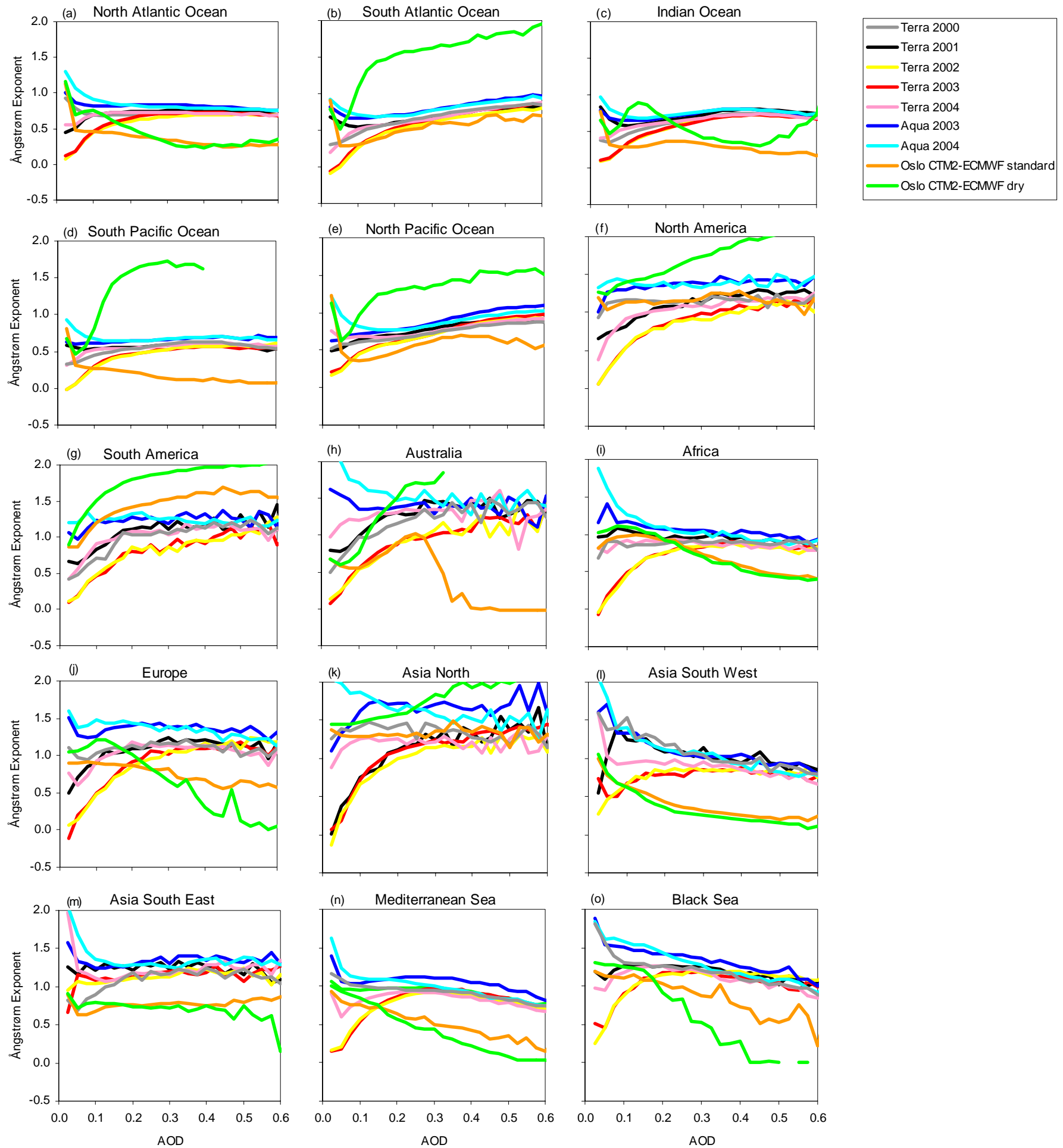

Fig. 9. As in Figs. 7a-o, but for Ångstrøm Exponent. Also shown are data from Oslo CTM2. 

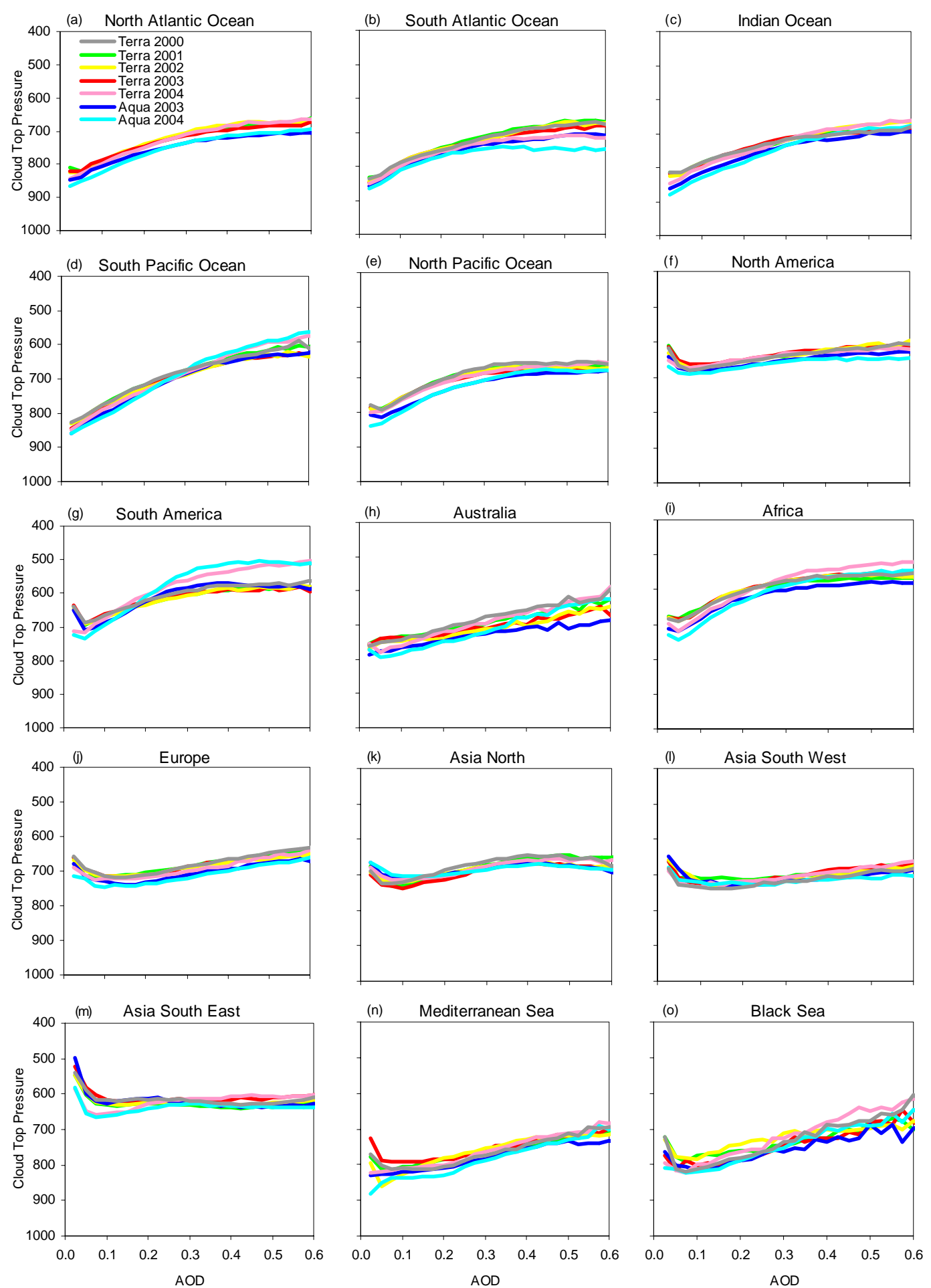

Fig. 10. As in Figs. 7a-o, but for cloud top pressure.

\subsubsection{Global scale}

The increase in the water vapour column is much stronger in the two models than in MODIS for low AOD (Fig. 6f). Significant differences between the results of the models can- not be explained by the hygroscopic effect of aerosols alone. The two models do not separate the water vapour column in a clear sky and above the clouds as in the MODIS data, thus complicating the comparison somewhat. 

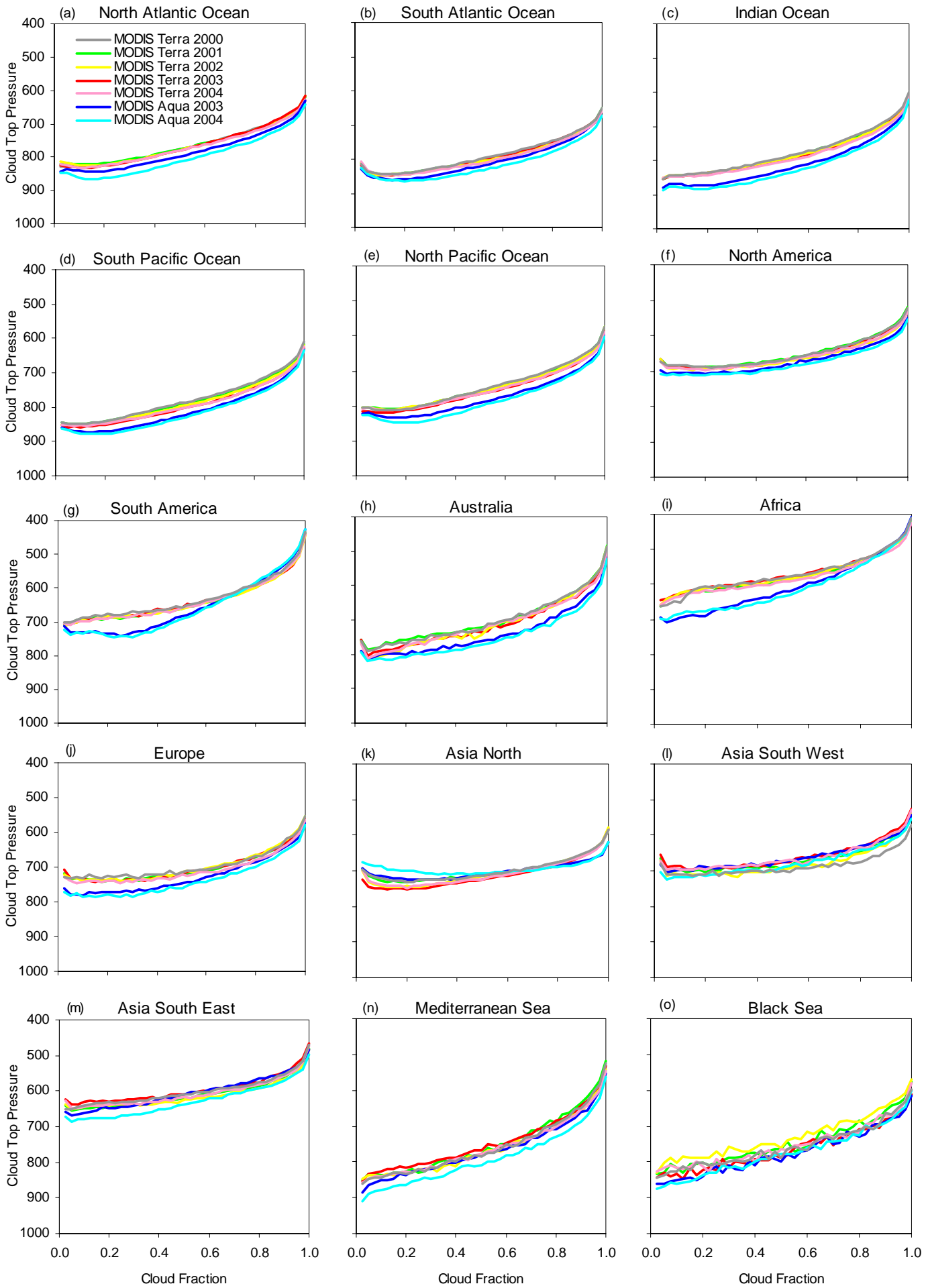

Fig. 11. As in Figs. 7a-o, but cloud top pressure as a function of cloud fraction.

\section{5 Ångstrøm exponent}

The Ångstrøm exponent increases mostly with AOD in the MODIS data, with some regional variations and interannual variations (Fig. 9). The results from the Aqua satellite differ from the results from Terra, especially for low AOD. Differing results between Terra and Aqua are not seen in the results shown in Fig. 5 for cloud fraction; see also Fig. 6b. The 

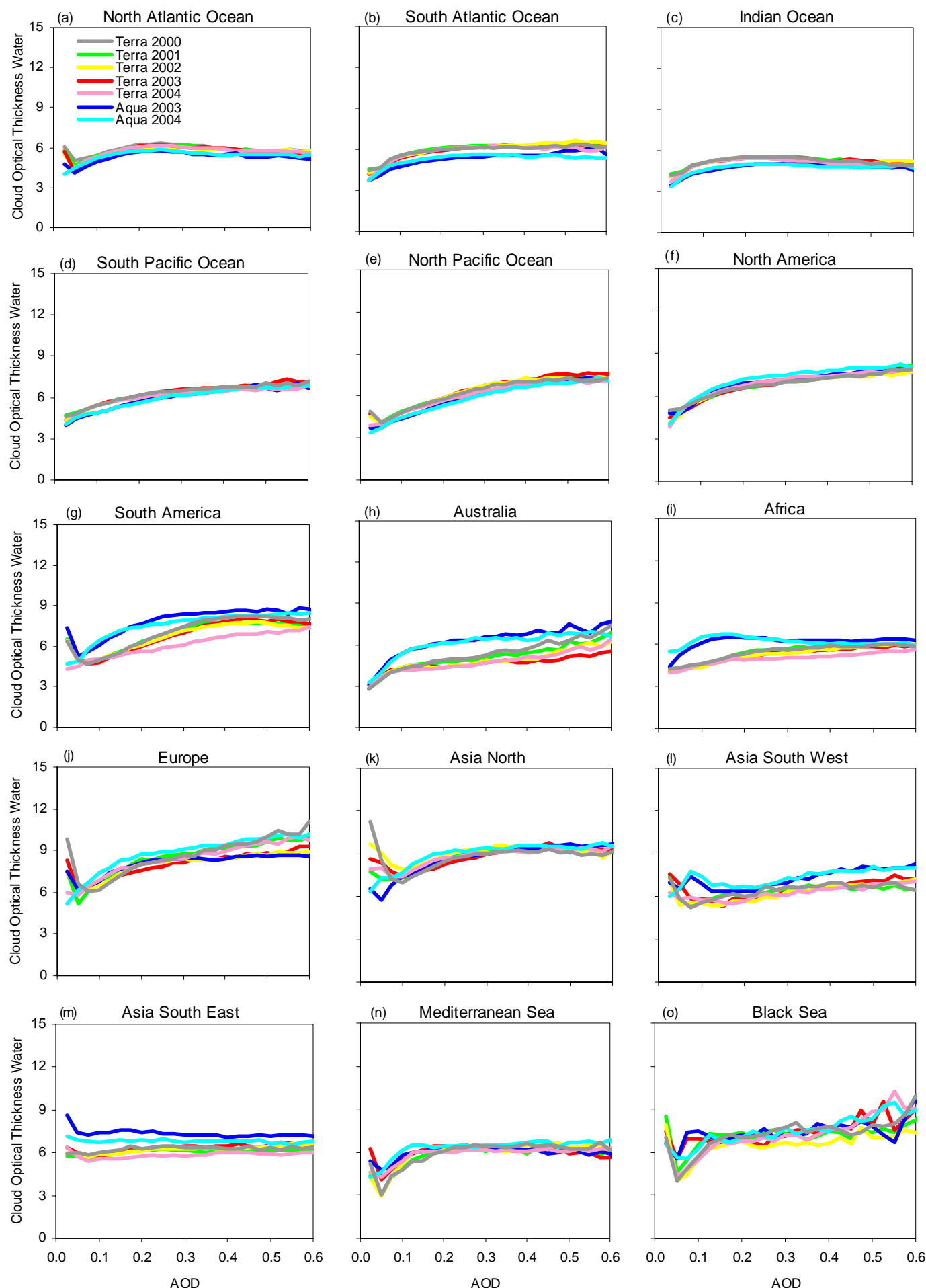

Fig. 12. As in Figs. 7a-o, but for cloud optical thickness.

prevailing trend that the Ångstrøm exponent increases with AOD is opposite to what would be the case if swelling of particles due to hygroscopic growth near cloudy areas played a major role in the MODIS data. The Ångstrøm exponent may also change if the ratio of the small and large mode particles changes. In the Oslo CTM2 the Ångstrøm exponent follows the MODIS Ångstrøm exponent in many regions but with a general tendency to decrease slightly more with AOD 

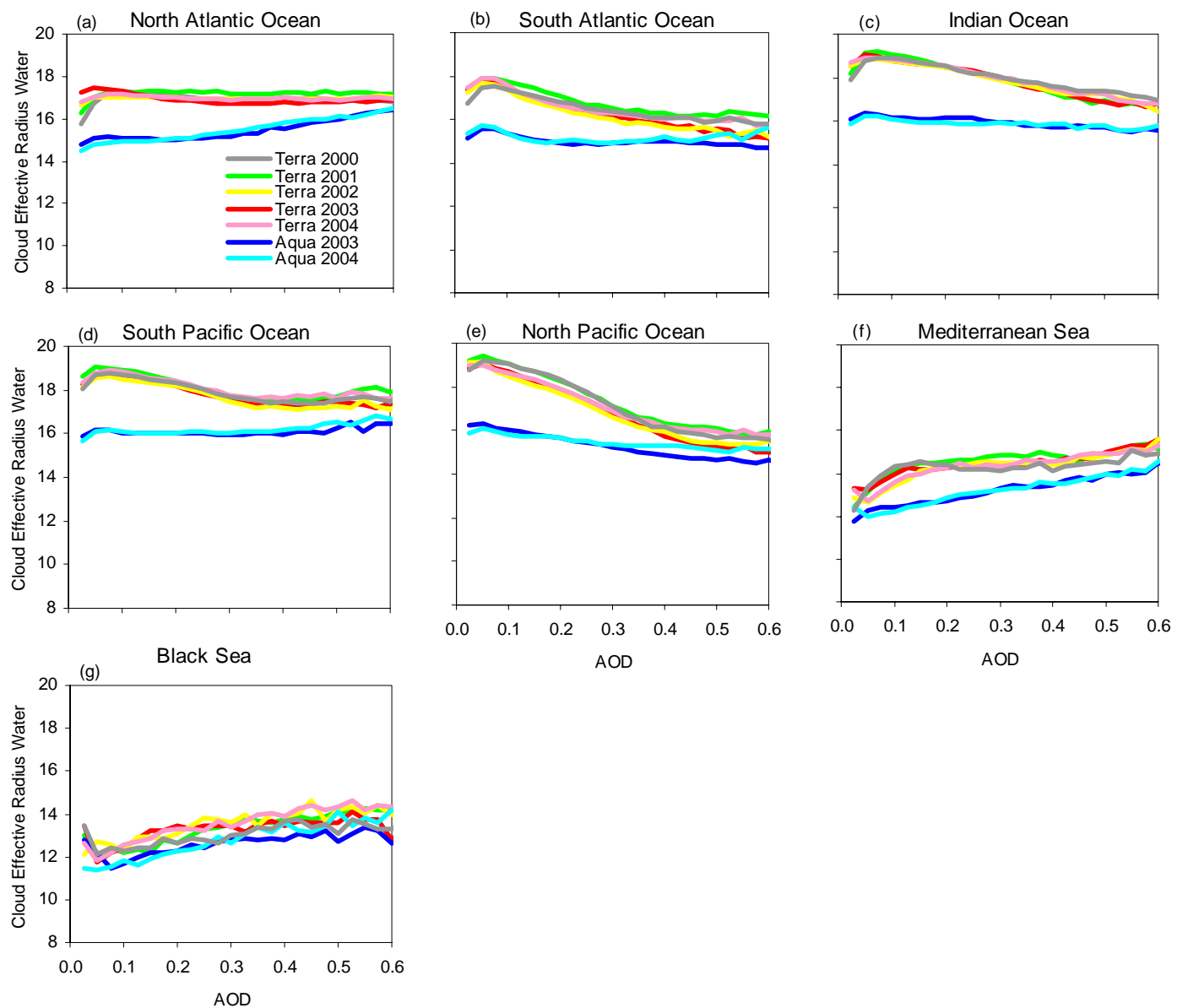

Fig. 13. As in Figs. 7a-g, but for cloud effective radius.

than the MODIS data do. In some of the regions the magnitude of the Ångstrøm exponent differs in the model compared to MODIS, most notably in two of the Asian regions. The model results for dry and standard cases for the Ångstrøm exponent show that the hygroscopic effect has a substantial impact on the results. A dry particle of anthropogenic origin may have an Ångstrøm exponent which is $60 \%$ higher than a particle with a growth factor of 1.6 , which illustrates that hygroscopic growth can substantially impact the Ångstrøm exponent.

\subsection{Cloud top pressure vs. cloud cover}

In Fig. 10 cloud top pressure (CTP) is shown as a function of AOD from MODIS. Except for very small AOD over some regions CTP decreases (higher cloud altitude) with increasing AOD, in accordance with other studies (Kaufman et al., 2005a; Koren et al., 2005). This may be a result of the suppression of the precipitation effect by extending the cloud lifetime (Andreae et al., 2004; Williams et al., 2002). Figure 11 shows cloud top pressure as a function of cloud cover. In the MODIS data a significant decrease in the CTP as a function of the cloud fraction is found. This decrease is very similar in the various regions. The reduction in CTP is largest at high cloud fractions. A relationship between AOD and cloud cover will thus also imply a relationship between AOD and CTP.

\section{Discussion}

\subsection{Causes for model differences}

The two models used in this study show a large spread in results, revealing differences that arise from the aerosol distribution, the effect of hygroscopic growth, other cloud processes, and meteorological situations. Most noticeable is the difference in the effect of hygroscopic growth, which is illustrated in Fig. 6c. The parameterizations made for the various hygroscopic aerosols are rather similar in the two global aerosol models. These depend on aerosol size and relative humidity. The growth factor (relative increase in aerosol size from a dry aerosol) increases with aerosol size. Therefore, if the CAM-Oslo model had larger aerosols than the OsloCTM2, this could contribute to the variation seen in the ef- 
fect of water uptake between the two models. However, the global aerosol modelling (AeroCom) exercise (Textor et al., 2006) shows that in fact the opposite is the case, since OsloCTM2 has slightly a larger fraction of coarse mode particles including hygroscopic aerosols. Note here that both models had aerosol sizes in reasonable agreement with the models involved in this intercomparison. Myhre et al. (2004) found that the relative humidity in the NCAR model was much higher than in the ECMWF data. This actually strengthened the direct aerosol effect of sulphate aerosols, using the NCAR relative humidity compared to ECMWF relative humidity by $60 \%$. The fraction of grid points with a relative humidity over $95 \%$ in the ECMWF data below $8 \mathrm{~km}$ is around $5 \%$ whereas in the NCAR data it is closer to $20 \%$. More emphasis should be made to validate the relative humidity fields in the global models due to its importance both for the direct aerosol effect and the indirect aerosol effect. The discrepancy in relative humidity is likely to be the main cause of the difference in the hygroscopic effect between the two models. Notice, however, that different versions of the NCAR model have been used in the NCAR based studies cited above and in this study.

\subsection{Implications for cloud cover}

No obvious relations between AOD and cloud cover were found in the two models without physical aerosol-cloudinteractions, in the case when hygroscopic growth was neglected. However, in general, there was a weak tendency that cloud cover decreased with AOD in these cases in the two models. This indicates that meteorological factors influence the relationship, for example, over land AOD and cloud cover are often inversely related as high pressure systems favour low cloud amounts and a build up of aerosols, whereas over the ocean storms lead to more clouds as well as sea salt aerosols. There is in most cases a strong increase in cloud cover with AOD in the MODIS data, which we interpret as a result of two factors. First, the largest impact seems to be a cloud cover increase, especially at low AOD, which is indicative of physical aerosol-cloud interactions. At low AOD (below $\sim 0.2$ ) there is an increase in cloud cover with AOD in the MODIS data which in almost all regions is stronger than in the models. Further, part of the increase in cloud cover, especially at larger AOD can, to some extent, be explained by larger hygroscopic growth near clouds. As the efficiency of the hygroscopic growth is crucial, the screening criteria for clouds in the MODIS retrievals are very important. Of crucial importance is also the hygroscopic nature of atmospheric aerosols and their representation in global aerosol models. Residual cloud contamination in the aerosol retrievals has been suggested to be a cause for the increase in cloud cover with AOD (Zhang et al., 2005), but Kaufman et al. (2005c) found the contamination to be low and to play an insignificant role in studies of aerosol-cloud interactions. The largest increase in cloud cover with AOD is at low AOD where cloud cover is also small. This is the situation where cloud contamination is expected to be weakest (Kaufman et al., 2005c; Zhang et al., 2005). Based on the various model simulations we have performed we find that use of relative humidity in the clear sky versus grid box averages and the choice of thresholds of cloud amounts are not of major importance. Our analyses from Fig. 3 indicate that the aerosol and cloud relations from some regions, in particular North America and Northern Asia, should be treated with care, as less confidence can be placed on the results in these regions compared to some of the oceanic regions where the relations are more unambiguous.

MODIS results indicate that the increase in AOD is not a major result of the hygroscopic growth, as the Ångstrøm exponent increases in many areas with AOD. Also, over the ocean, where the MODIS aerosol retrieval has smaller uncertainty than over land, there are more regions with an increase than a decrease in the Ångstrøm exponent with AOD but not in all regions. This is opposite to what would be expected if water uptake was the primary cause. The model results for the Ångstrøm exponent also indicate that there is a large humidification effect. In this respect there is reasonable agreement between the model and the MODIS data. Our results show a strong increase in cloud cover with AOD for small AODs, which is in line with the suppression of the precipitation effect (aerosols mostly increase the cloud cover) and less with the semi-direct effect (aerosols mostly decrease the cloud cover). It is shown that the semi-direct effect may even increase cloud cover (Johnson et al., 2004) and it may therefore not be ruled out. Further, the general lack of increase in cloud cover for AOD higher than $\sim 0.2$ may be influenced by the semi-direct aerosol effect.

We find a doubling of the cloud cover for a change in the AOD from 0.05 to 0.2. As stated in the Introduction, this supports the mechanism of transition change from open to closed Benard cells over ocean (Rosenfeld et al., 2006). Over land that mechanism has not been observed, and, respectively, the cloud fraction increase with AOD is more blurred and occurs over a wider range of AOD. At the very large AOD the inverse occurs over land, and this could be explained by the mechanism described by Koren et al. (2004).

\subsection{Consequences for other cloud parameters}

The model simulations of the relationships between AOD and water vapour, as well as AOD and LWP, show that meteorological conditions influence the analysis significantly. In a few results the hygroscopic growth of the aerosols also plays an important role. The MODIS data show generally a weaker increase in these water quantities with AOD than the models but firm conclusions from these simulations seem difficult and further analysis is necessary.

Based on the analysis performed here MODIS results of the relationship between AOD and cloud optical depth (Fig. 12), as well as AOD and effective radius (Fig. 13), must 
be treated with care (Marshak et al. (2006) discuss the possibility that the cloud effective radius is overestimated). The cloud optical depth shows an increase with AOD and mostly the effective radius shows a decrease with AOD, in accordance with the classical theory (Twomey, 1977). The cloud effective radius appears in some places (e.g. the Mediterranean) to paradoxically increase with AOD. But this is probably primarily a manifestation of the observation that cloud top pressure decreases there too with AOD, because the cloud effective radius increases with a decreasing cloud top pressure of convective clouds (Rosenfeld and Lensky, 1998). This is supported by the cloud fraction increase with AOD and cloud top pressure decrease with cloud fraction in the Mediterranean. The LWP also increases with AOD (Fig. 7) and thus also contributes to an increased cloud optical depth with AOD. However, since we have seen that hygroscopic growth and meteorological factors influence the relationships of other cloud parameters with AOD, it is not obvious that this can be ruled out for cloud optical depth and effective radius.

The MODIS data consist of an enormous amount of data which are valuable for understanding how aerosols influence clouds. The analysis here shows that the hygroscopic behaviour of aerosols introduces a complicating factor, so that the aerosol-cloud analysis needs to be made by combining several tools. Further, care must be taken since several of the cloud parameters in the MODIS data are correlated, such as, for example, cloud cover and cloud top pressure. As AOD and cloud cover are related, AOD and cloud top pressure will also show a clear relation.

\section{Summary}

Based on MODIS satellite data in combination with global aerosol models we have found that the cloud fraction increases with AOD on a global scale and that most of this is likely linked to aerosol-cloud interactions. We have split the results at $\mathrm{AOD}=0.2$ since the results differ for $\mathrm{AOD}$ above and below this number. The most clear cloud-aerosol effect is observed for cloud fraction at $\mathrm{AOD}<0.2$, in the most pronounced way over the "marine" ocean (Fig. 4) and it is limited to smaller AOD ranges over oceans than over land. We find a doubling of the cloud cover for a change in the AOD from 0.05 to 0.2 . We find that the cloud fraction increase with AOD is relatively independent of aerosol chemical composition, in accordance with the finding in Dusek et al. (2006) that aerosol size distribution is much more important for the cloud condensation nuclei concentration. In the MODIS data we find some weak regional variations in the increase in cloud cover with AOD, but these are anyway small variations despite the large variations in aerosol composition. One uncertainty regarding the results for cloud fraction is related to the hygroscopic nature of the aerosols, complicating the quantification of the impact of aerosol-cloud interactions.
Model results in this study have been useful in studying the impact of large and mesoscale weather systems on the aerosol - cloud relationship, as well as in documenting that the aerosol hygroscopic effect has an influence on this relationship. However, the models have not given us the ability to quantify the influence of the hygroscopic effect on the AOD - clouds relationship due to their coarse horizontal resolution. The models have neither been very useful in studies of the aerosol impact on water vapour and LWP.

We show that cloud top pressure decreases with AOD globally and impacts how the cloud effective radius changes with AOD. Thus, the suppression of the precipitation effect impacts the cloud albedo effect by altering the cloud top pressure. It is difficult to draw conclusions from our results on the LWP and water vapour column, indicating whether anthropogenic aerosols impact the hydrological cycle. In general, there are many relations between the various parameters, both related to cloud microphysics and meteorology. Thus, establishing cause and effect relationships between parameters is difficult and must be made with care.

Edited by: W. Conant

\section{References}

Ackerman, A. S., Toon, O. B., Stevens, D. E., Heymsfield, A. J., Ramanathan, V., et al.: Reduction of tropical cloudiness by soot, Science, 288(5468), 1042-1047, 2000.

Albrecht, B. A.: Aerosols, Cloud Microphysics, And Fractional Cloudiness, Science, 245(4923), 1227-1230, 1989.

Anderson, T. L., Charlson, R. J., Schwartz, S. E., Knutti, R., Boucher, O., et al.: Climate forcing by aerosols - a hazy picture, Science, 300(5622), 1103-1104, 2003.

Andreae, M. O., Rosenfeld, D., Artaxo, P., Costa, A. A., Frank, G. P., et al.: Smoking rain clouds over the Amazon, Science, 303(5662), 1337-1342, 2004.

Berglen, T. F., Berntsen, T. K., Isaksen, I. S. A., and Sundet, J. K.: A global model of the coupled sulfur/oxidant chemistry in the troposphere: The sulfur cycle, J. Geophys. Res.-Atmos., 109(D19), D19310, doi:10.1029/2003JD003948, 2004.

Boucher, O., Myhre, G., Myhre, A.: Direct human influence of irrigation on atmospheric water vapour and climate, Clim. Dynam., 22, 597-603, 2004.

Breon, F. M., Tanre, D., and Generoso, S.: Aerosol effect on cloud droplet size monitored from satellite, Science, 295(5556), 834838, 2002.

Cook, J. and Highwood, E. J.: Climate response to tropospheric absorbing aerosols in an intermediate general-circulation model, Q. J. Roy. Meteor. Soc., 130(596), 175-191, 2004.

Dentener, F., Kinne, S., Bond, T., Boucher, O., Cofala, J., et al.: Emissions of primary aerosol and precursor gases in the year 2000 and 1750 prescribed data-sets for AeroCom, Atmos. Chem. Phys., 6, 4321-4344, 2006, http://www.atmos-chem-phys.net/6/4321/2006/.

Dusek, U., Frank, G. P., Hildebrandt, L., Curtius, J., Schneider, J., et al.: Size matters more than chemistry for cloud-nucleating ability of aerosol particles, Science, 312(5778), 1375-1378, 2006. 
Feingold, G., Eberhard, W. L., Veron, D. E., and Previdi, M.: First measurements of the Twomey indirect effect using ground-based remote sensors, Geophys. Res. Lett., 30(6), 1287, doi:10.1029/2002GL016633, 2003.

Forest, C. E., Stone, P. H., Sokolov, A. P., Allen, M. R., and Webster, M. D.: Quantifying uncertainties in climate system properties with the use of recent climate observations, Science, 295(5552), 113-117, 2002.

Gunn, R. and Phillips, B. B.: An Experimental Investigation Of The Effect Of Air Pollution On The Initiation Of Rain, J. Meteorol., 14(3), 272-280, 1957.

Houghton, J. T., Ding, Y., Griggs, D. J., Noguer, M., et al. (Eds.): Climate Change 2001: The Scientific Basis. Contribution of Working Group I to the Third Assessment Report of the Intergovernmental Panel on Climate Change, Cambridge Univ. Press, UK/USA, 2001.

Iversen, T. and Seland, O.: A scheme for process-tagged SO4 and BC aerosols in NCAR CCM3: Validation and sensitivity to cloud processes, J. Geophys. Res.-Atmos., 107(D24), 4751, doi:10.1029/2001JD000885, 2002.

Johnson, B. T., Shine, K. P., and Forster, P. M.: The semi-direct aerosol effect: Impact of absorbing aerosols on marine stratocumulus, Q. J. Roy. Meteor. Soc., 130(599), 1407-1422, 2004.

Karl, T. R. and Steurer, P. M.: Increased Cloudiness In The UnitedStates During The 1st-Half Of The 20th-Century - Fact Or Fiction, Geophys. Res. Lett., 17(11), 1925-1928, 1990.

Kaufman, Y. J., Boucher, O., Tanre, D., Chin, M., Remer, L. A., et al.: Aerosol anthropogenic component estimated from satellite data, Geophys. Res. Lett., 32(17), L17804, doi:10.1029/2005GL023125, 2005b.

Kaufman, Y. J. and Fraser, R. S.: The effect of smoke particles on clouds and climate forcing, Science, 277(5332), 1636-1639, 1997.

Kaufman, Y. J., Koren, I., Remer, L. A., Rosenfeld, D., and Rudich, Y.: The effect of smoke, dust, and pollution aerosol on shallow cloud development over the Atlantic Ocean, Proc. Natl. Acad. Sci., 102(32), 11 207-11 212, 2005a.

Kaufman, Y. J., Remer, L. A., Tanre, D., Li, R. R., Kleidman, R., et al.: A critical examination of the residual cloud contamination and diurnal sampling effects on MODIS estimates of aerosol over ocean, IEEE Transact. Geosci. Rem. Sens., 43(12), 2886-2897, 2005c.

Kaufman, Y. J., Tanre, D., and Boucher, O.: A satellite view of aerosols in the climate system, Nature, 419(6903), 215-223, 2002.

Kaufman, Y. J., Tanre, D., Remer, L. A., Vermote, E. F., Chu, A., et al.: Operational remote sensing of tropospheric aerosol over land from EOS moderate resolution imaging spectroradiometer, J. Geophys. Res.-Atmos., 102(D14), 17 051-17 067, 1997.

Khain, A., Rosenfeld, D., and Pokrovsky, A.: Aerosol impact on the dynamics and microphysics of deep convective clouds, Q. J. Roy. Meteor. Soc., 131(611), 2639-2663, 2005.

Kim, B. G., Schwartz, S. E., Miller, M. A., and Min, Q. L.: Effective radius of cloud droplets by ground-based remote sensing: Relationship to aerosol, J. Geophys. Res.-Atmos., 108(D23), 4740, doi:10.1029/2003JD003721, 2003.

Kirkevåg, A. and Iversen, T.: Global direct radiative forcing by process-parameterized aerosol optical properties, J. Geophys. Res.-Atmos., 107(D20), 4433, doi:10.1029/2001JD000886,
2002.

Knutti, R., Stocker, T. F., Joos, F., and Plattner, G. K.: Constraints on radiative forcing and future climate change from observations and climate model ensembles, Nature, 416(6882), 719-723, 2002.

Koren, I., Kaufman, Y. J., Remer, L. A., and Martins, J. V.: Measurement of the effect of Amazon smoke on inhibition of cloud formation, Science, 303(5662), 1342-1345, 2004.

Koren, I., Kaufman, Y. J., Rosenfeld, D., Remer, L. A., and Rudich, Y.: Aerosol invigoration and restructuring of Atlantic convective clouds, Geophys. Res. Lett., 32(14), L14828, doi:10.1029/2005GL023187, 2005.

Lohmann, U. and Feichter, J.: Global indirect aerosol effects: a review, Atmos. Chem. Phys., 5, 715-737, 2005, http://www.atmos-chem-phys.net/5/715/2005/.

Lohmann, U., Koren, I., and Kaufman, Y. J.: Disentangling the role of microphysical and dynamical effects in determining cloud properties over the Atlantic, Geophys. Res. Lett., 33, L09802, doi:10.1029/2005GL024625, 2006.

Marshak, A., Platnick, S., Varnai, T., Wen, G., and Cahalan, R. F.: Impact of three-dimensional radiative effects on satellite retrievals of cloud droplet sizes, J. Geophys. Res.-Atmos., 111, D09207, doi:10.1029/2005JD006686, 2006.

Menon, S., Hansen, J., Nazarenko, L., and Luo, Y. F.: Climate effects of black carbon aerosols in China and India, Science, 297(5590), 2250-2253, 2002.

Myhre, G., Stordal, F., Berglen, T. F., Sundet, J. K., and Isaksen, I. S. A.: Uncertainties in the radiative forcing due to sulfate aerosols, J. Atmos. Sci., 61(5), 485-498, 2004.

Myhre, G., Bellouin, N., Berglen, T. F., Berntsen, T. K., Boucher, O., et al.: Comparison of the radiative properties and direct radiative effect of aerosols from a global aerosol model and remote sensing data over ocean, Tellus, 59B, 115-129, 2007.

Norris, J. R.: On trends and possible artifacts in global ocean cloud cover between 1952 and 1995, J. Climate, 12(6), 1864-1870, 1999.

Penner, J. E., Dong, X. Q., and Chen, Y.: Observational evidence of a change in radiative forcing due to the indirect aerosol effect, Nature, 427(6971), 231-234, 2004.

Penner, J. E., Zhang, S. Y., and Chuang, C. C.: Soot and smoke aerosol may not warm climate, J. Geophys. Res.-Atmos., 108(D21), 4657, doi:10.1029/2003JD003409, 2003.

Platnick, S., King, M. D., Ackerman, S. A., Menzel, W. P., Baum, B. A., et al.: The MODIS cloud products: Algorithms and examples from Terra, IEEE Transact. Geosci. Rem. Sens., 41(2), 459-473, 2003.

Ramanathan, V., Crutzen, P. J., Kiehl, J. T., and Rosenfeld, D.: Atmosphere - Aerosols, climate, and the hydrological cycle, Science, 294(5549), 2119-2124, 2001.

Remer, L. A., Kaufman, Y. J., Tanre, D., Mattoo, S., Chu, D. A., et al.: The MODIS aerosol algorithm, products, and validation, J. Atmos. Sci., 62(4), 947-973, 2005.

Rosenfeld, D.: TRMM observed first direct evidence of smoke from forest fires inhibiting rainfall, Geophys. Res. Lett., 26(20), 31053108, 1999.

Rosenfeld, D.: Suppression of rain and snow by urban and industrial air pollution, Science, 287(5459), 1793-1796, 2000.

Rosenfeld, D., Kaufman, Y. J., and Koren, I.: Switching cloud cover and dynamical regimes from open to closed Benard cells in re- 
sponse to supression of precipitation by aerosols, Atmos. Chem. Phys., 6, 2503-2511, 2006,

http://www.atmos-chem-phys.net/6/2503/2006/.

Rosenfeld, D., Lahav, R., Khain, A., and Pinsky, M.: The role of sea spray in cleansing air pollution over ocean via cloud processes, Science, 297(5587), 1667-1670, 2002.

Rosenfeld, D.: Aerosol-cloud interactions control of Earth radiation and latent heat release budgets, Space Sci. Rev., 125, 149-157, 2006.

Rosenfeld, D. and Lensky, I. M.: Satellite-based insights into precipitation formation processes in continental and maritime convective clouds, B. Am. Meteorol. Soc., 79(11), 2457-2476, 1998.

Schwartz, S. E., Harshvardhan, and Benkovitz, C. M.: Influence of anthropogenic aerosol on cloud optical depth and albedo shown by satellite measurements and chemical transport modeling, Proc. Natl. Acad. Sci., 99(4), 1784-1789, 2002.

Sekiguchi, M., Nakajima, T., Suzuki, K., Kawamoto, K., Higurashi, A., et al.: A study of the direct and indirect effects of aerosols using global satellite data sets of aerosol and cloud parameters, J. Geophys. Res.-Atmos., 108(D22), 4699, doi:10.1029/2002JD003359, 2003.

Storelvmo, T., Kristjansson, J. E., Myhre, G., Johnsrud, M., Stordal, F.: Combined observational and modeling based study of the aerosol indirect effect, Atmos. Chem. Phys., 6, 3583-3601, 2006, http://www.atmos-chem-phys.net/6/3583/2006/.

Sun, B. M. and Groisman, P. Y.: Variations in low cloud cover over the United States during the second half of the twentieth century, J. Climate, 17(9), 1883-1888, 2004.
Tanré, D., Kaufman, Y. J., Herman, M., and Mattoo, S.: Remote sensing of aerosol properties over oceans using the MODIS/EOS spectral radiances, J. Geophys. Res.-Atmos., 102(D14), $16971-$ 16988, 1997.

Textor, C., Schulz, M., Guibert, S., Kinne, S., Balkanski, Y., et al.: Analysis and quantification of the diversities of aerosol life cycles within AeroCom, Atmos. Chem. Phys., 6, 1777-1813, 2006, http://www.atmos-chem-phys.net/6/1777/2006/.

Trenberth, K. E., Fasullo, J., and Smith, L.: Trends and variability in column-integrated atmospheric water vapor, Clim. Dynam., 24, 741-758, 2005.

Tuomenvirta, H., Alexandersson, H., Drebs, A., Frich, P., and Nordli, P. O.: Trends in Nordic and Arctic temperature extremes and ranges, J. Climate, 13(5), 977-990, 2000.

Twomey, S.: Influence Of Pollution On Shortwave Albedo Of Clouds, J. Atmos. Sci., 34(7), 1149-1152, 1977.

Williams, E., Rosenfeld, D., Madden, N., Gerlach, J., Gears, N., et al.: Contrasting convective regimes over the Amazon: Implications for cloud electrification, J. Geophys. Res.-Atmos., 107(D20), 8082, doi:10.1029/2001JD000380, 2002.

Zhang, J. L., Reid, J. S., and Holben, B. N.: An analysis of potential cloud artifacts in MODIS over ocean aerosol optical thickness products, Geophys. Res. Lett., 32(15), L15803, doi:10.1029/2005GL023254, 2005. 